\title{
Attenuated immune control of Epstein-Barr virus in humanized mice is associated with the multiple sclerosis risk factor HLA-DR15
}

Zdimerova, Hana ; Murer, Anita ; Engelmann, Christine ; Raykova, Ana ; Deng, Yun ; Gujer, Cornelia ; Rühl, Julia ; McHugh, Donal ; Caduff, Nicole ; Naghavian, Reza ; Pezzino, Gaetana ; Capaul, Riccarda ; Zbinden, Andrea ; Ferlazzo, Guido ; Lünemann, Jan D ; Martin, Roland ; Chatterjee, Bithi ; Münz, Christian

\begin{abstract}
Immune responses to Epstein-Barr virus (EBV) infection synergize with the main genetic risk factor HLA-DRB1*15:01 (HLA-DR15) to increase the likelihood to develop the autoimmune disease multiple sclerosis (MS) at least sevenfold. In order to gain insights into this synergy, we investigated HLA-DR15 positive human immune compartments after reconstitution in immune-compromised mice (humanized mice) with and without EBV infection. We detected elevated activation of both CD4 ${ }^{+}$and $\mathrm{CD}^{+} \mathrm{T}$ cells in HLA-DR15 donor-reconstituted humanized mice at steady state, even when compared to immune compartments carrying HLA-DRB1*04:01 (HLA-DR4), which is associated with other autoimmune diseases. Increased $\mathrm{CD}^{+} \mathrm{T}$ cell expansion and activation was also observed in HLA-DR15 donor-reconstituted humanized mice after EBV infection. Despite this higher immune activation, EBV viral loads were less well controlled in the context of HLA-DR15. Indeed, HLA-DR15-restricted CD4 ${ }^{+}$ T cell clones recognized EBV-transformed B cell lines less efficiently and demonstrated cross-reactivity toward allogeneic target cells and one MS autoantigen. These findings suggest that EBV as one of the main environmental risk factors and HLA-DR15 as the main genetic risk factor for MS synergize by priming hyperreactive T-cell compartments, which then control the viral infection less efficiently and contain cross-reactive $\mathrm{CD} 4^{+} \mathrm{T}$ cell clones.
\end{abstract}

DOI: https://doi.org/10.1002/eji.202048655

Posted at the Zurich Open Repository and Archive, University of Zurich

ZORA URL: https://doi.org/10.5167/uzh-192918

Journal Article

Accepted Version

Originally published at:

Zdimerova, Hana; Murer, Anita; Engelmann, Christine; Raykova, Ana; Deng, Yun; Gujer, Cornelia; Rühl, Julia; McHugh, Donal; Caduff, Nicole; Naghavian, Reza; Pezzino, Gaetana; Capaul, Riccarda; Zbinden, Andrea; Ferlazzo, Guido; Lünemann, Jan D; Martin, Roland; Chatterjee, Bithi; Münz, Christian (2021). Attenuated immune control of Epstein-Barr virus in humanized mice is associated with the multiple sclerosis risk factor HLA-DR15. European Journal of Immunology, 51(1):64-75.

DOI: https://doi.org/10.1002/eji.202048655 
Attenuated immune control of Epstein Barr virus in humanized mice is associated with the multiple sclerosis risk factor HLA-DR15

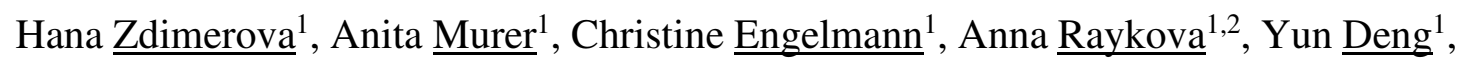

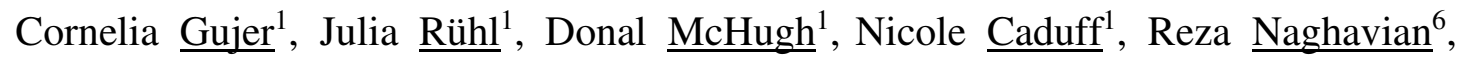
Gaetana $\underline{\text { Pezzino }}^{3}$, Riccarda $\underline{\text { Capaul }}^{4}$, Andrea $\underline{\text { Zbinden }}^{4}$, Guido $\underline{\text { Ferlazzo }}^{3}$, Jan D. $\underline{\text { Lünemann }}^{5}$, Roland $\underline{\text { Martin }}^{6}$, Bithi $\underline{\text { Chatterjee }}^{1 *}$, and Christian $\underline{\text { Münz }}^{1 *}$

${ }^{1}$ Viral Immunobiology, Institute of Experimental Immunology, University of Zürich, Zürich, Switzerland

${ }^{2}$ Department for BioMedical Research, University of Bern, Bern, Switzerland.

${ }^{3}$ Laboratory of Immunology and Biotherapy, Department of Human Pathology, University of Messina, Messina, Italy; Cell Factory Center, University of Messina, Messina, Italy; Cell Therapy Program, University Hospital Policlinico G.Martino, Messina, Italy; Division of Clinical Pathology, University Hospital Policlinico G.Martino, Messina, Italy.

${ }^{4}$ Institute of Medical Virology, University of Zürich, Zürich, Switzerland.

${ }^{5}$ Department of Neurology with Institute of Translational Neurology, Medical Faculty, University of Münster, Münster, Germany.

${ }^{6}$ Neuroimmunology and MS Research Section, Neurology Clinic, University Zurich, University Hospital Zurich, Zurich, Switzerland.

*contributed equally

Key words: Epstein Barr virus, multiple sclerosis, autoimmunity, T cells, HLA-DR 
Address correspondence to: Christian Münz, Viral Immunobiology, Institute of Experimental Immunology, University of Zürich, Winterthurerstrasse 190, CH-8057 Zürich, Switzerland. Tel: +41-44-635-3716, +41-44-635-3701, Fax: +41-44-635-6883, e-mail: christian.muenz@uzh.ch

\begin{abstract}
Abbreviations: EBV (Epstein Barr virus), MS (multiple sclerosis), MHC (major histocompatibility complex), HLA (human leukocyte antigen), IM (infectious mononucleosis), CNS (central nervous system), huNSG (humanized NOD-scid IL2 receptor $\gamma$-chain-deficient), BLCL (bare lymphocyte syndrome lymphoblastoid cell line), EBNA1 (EBV nuclear antigen 1), Ig (immunoglobulin)
\end{abstract}




\section{ABSTRACT}

Immune responses to Epstein Barr virus (EBV) infection synergize with the main genetic risk factor HLA-DRB1*15:01 (HLA-DR15) to increase the likelihood to develop the autoimmune disease multiple sclerosis (MS) at least seven-fold. In order to gain insights into this synergy, we investigated HLA-DR15 positive human immune compartments after reconstitution in immune compromised mice (humanized mice) with and without EBV infection.

We detected elevated activation of both $\mathrm{CD}^{+}{ }^{+}$and $\mathrm{CD}^{+} \mathrm{T}$ cells in HLA-DR15 donor-reconstituted humanized mice at steady state, even when compared to immune compartments carrying HLA-DRB1*04:01 (HLA-DR4), which is associated with other autoimmune diseases. Increased $\mathrm{CD}^{+} \mathrm{T}$ cell expansion and activation was also observed in HLA-DR15 donor-reconstituted humanized mice after EBV infection. Despite this higher immune activation, EBV viral loads were less well controlled in the context of HLA-DR15. Indeed, HLA-DR15-restricted CD4 ${ }^{+} \mathrm{T}$ cell clones recognized EBV-transformed B cell lines less efficiently and demonstrated cross-reactivity towards allogeneic target cells and one MS autoantigen.

These findings suggest that EBV as one of the main environmental risk factors and HLA-DR15 as the main genetic risk factor for MS synergize by priming hyperreactive $\mathrm{T}$ cell compartments, which then control the viral infection less efficiently and contain cross-reactive $\mathrm{CD} 4^{+} \mathrm{T}$ cell clones. 


\section{INTRODUCTION}

Multiple sclerosis (MS) is an inflammatory, demyelinating disease of the central nervous system (CNS) that often leads to substantial decline of sensory, motor, autonomic and neurocognitive functions. While considered to be an autoimmune, $\mathrm{CD} 4^{+}$ T cell-mediated disorder, its etiology still remains poorly understood [1].

Genome-wide association studies have identified the human leukocyte antigen (HLA) allele HLA-DRB1*15:01 (HLA-DR15) as the strongest associated genetic risk factor for MS. Other identified loci represent mainly immunologically relevant genes, particularly suggesting a role for helper $\mathrm{T}$ cell differentiation and function in MS pathogenesis $[2,3]$.

As the genetic background confers only partial risk for the disease, the role for environmental risk factors and their synergies with MS genetics have become increasingly apparent, especially in the first two decades of life [4]. Altered immune response to the Epstein Barr virus (EBV), including immunopathology during the acute primary EBV infection, called infectious mononucleosis (IM), is associated with MS and synergizes with HLA-DR15 resulting in a seven-fold increased risk of the disease [5]. The mechanisms behind this synergy remain unclear.

EBV is a ubiquitous $\gamma$-herpesvirus infecting around $95 \%$ of the world adult population [6]. Following oral transmission, it starts a latent, growth transforming infection of B cells and persists in their memory compartment [7]. EBV is generally acquired early in childhood and leads to an asymptomatic primary infection at young age. However, if acquired in adolescence or early adulthood, it can manifest as IM [6], an acute illness sparking a vigorous immune response, characterized mainly by immensely expanded EBV-specific $\mathrm{CD}^{+} \mathrm{T}$ cells $[8,9]$. Immunopathogenic and 
exaggerated T cell responses are likely involved in IM being a phenomenon largely of late primary infection $[10,11]$.

Viral and infectious agents have since a long time been thought to play a role in MS $[12,13]$. Importantly, two studies demonstrated near-complete EBV seropositivity in pediatric MS patients $[14,15]$. In addition, adult MS patients all became EBV positive prior to disease onset, suggesting that MS risk is extremely low in EBV seronegative individuals, but increases sharply after EBV infection [16] and even further after IM [17, 18]. Indeed, higher anti-EBV antibody titers before MS onset [19] are associated with disease risk [20]. The genetic risk for elevated anti-EBV nuclear antigen 1 (EBNA1) IgG titers also correlates with MS development [21] and the risk markedly increases in HLA-DRB1*15:01 positive individuals [22].

However, adequate models are missing to study these interactions. Using a humanized mouse model (huNSG) of EBV infection, we investigated the role of HLADR15 in the immune control of EBV. Using data accumulated in our laboratory over several years, we were able to stratify animals reconstituted with HLA-DR15 positive and negative donors. We have demonstrated that $\mathrm{T}$ cells from HLA-DR15 positive donors have higher basal activation levels. Despite enhanced T cell proliferation, EBV viral loads are elevated which suggests an impaired T cell-mediated immune control of EBV under the restriction of HLA-DR15. Importantly, we also find evidence for CD4+ T cell cross-reactivity to the MS autoantigen myelin basic protein (MBP), as well as increased alloreactivity in $\mathrm{CD}^{+} \mathrm{T}$ cell clones derived from HLA-DR15 individuals. Our data offers insights into the gene-environment interactions that could lead or add to the perturbed $\mathrm{T}$ cell homeostasis in MS. 


\section{RESULTS}

\section{HLA-DR15 ${ }^{+}$donors reconstitute hyperactive T cells in huNSG animals}

We first wanted to investigate the effect of HLA-DR15 positive donors on $\mathrm{T}$ cell activation at steady state in humanized NOD-scid IL2 receptor $\gamma$-chain-deficient (huNSG) mice, as the major histocompatibility complex (MHC) Class II molecule HLA-DR15 carries the strongest genetic risk for multiple sclerosis [2]. To this end, we combined and stratified data from more than 3500 mice spanning six years of reconstitution experiments. This data was opportunistically pooled and was obtained by the same flow cytometry panel throughout (Fig. 1A, B, gating strategy is shown in Fig. S1, Fig. S2). Briefly, following intrahepatic injection of human fetal liver-derived human hematopoietic progenitor cells (i.e. donor) shortly after birth, animals were routinely bled after 3 months to check for the reconstitution of human immune system components in peripheral blood at steady state. Animals reconstituted with HLA-DR15 positive donors demonstrated a higher activation of total $\mathrm{T}$ cells, $\mathrm{CD} 4^{+}$and $\mathrm{CD}^{+} \mathrm{T}$ cells when compared to animals reconstituted with HLA-DR15 negative donors (Fig. 1A, Fig. S2A, B). This $\mathrm{T}$ cell activation was mainly observed among $\mathrm{CD} 4^{+} \mathrm{T}$ cells, which constitute around two thirds of the T cells after reconstitution. Furthermore, a higher activation frequency in the T cell compartment was also seen upon reconstitution with HLA-DR15 positive donors when compared with donors positive for HLA-DR4 (Fig. 1B), an MHC Class II molecule implicated in other autoimmune diseases, including rheumatoid arthritis and type I diabetes [23, 24]. Interestingly, a difference in $\mathrm{CD}^{+} \mathrm{T}$ cell activation was not observed when HLA-DR4 positive versus negative donors (HLA-DR15 exclusive) were compared (Fig. S2C). These findings illustrate that HLA-DR15 hematopoietic progenitor cells reconstitute hyperactive T cells in the huNSG mouse model at steady state. 
HLA-DR15 alters $C D 8^{+} T$ cell frequencies and activation during $E B V$ infection of huNSG mice

One of the hallmarks of IM is the vast expansion of $\mathrm{CD}^{+} \mathrm{T}$ cells, which are key to the immune control of EBV [25]. As the huNSG mouse model has been successfully used to study IM-like EBV infection [26], we examined the expansion of T cells following EBV infection in animals reconstituted with donors positive or negative for HLADR15.

During these experiments, animals were infected with a high dose $\left(10^{5}\right.$ infectious units) of the B95-8 strain of EBV and monitored for four to six weeks (Fig. 2A). We first wanted to investigate $\mathrm{T}$ cell expansion following EBV infection at time of sacrifice (Fig. 2B to I). Even though EBV infection induces a large expansion of $\mathrm{CD}^{+} \mathrm{T}$ cells, we observed even higher frequencies (Fig. 2B, C) and total numbers (Fig. 2D, E) in huNSG mice reconstituted with HLA-DR15 positive versus negative donors in both blood and spleen. While we did not observe a difference in the frequencies of $\mathrm{CD}^{+} \mathrm{T}$ cells (Fig. 2F, G) and total numbers in spleen (Fig. 2I), we did see higher total numbers of $\mathrm{CD}^{+} \mathrm{T}$ cells in the blood of HLA-DR15 reconstituted animals (Fig. $2 \mathrm{H}$ ).

In addition, there were higher numbers of activated $\mathrm{CD} 8^{+} \mathrm{T}$ cells (Fig. 3A, B) in blood and spleen of HLA-DR15 reconstituted animals, even though no differences were observed in the activation of the $\mathrm{CD}^{+}{ }^{+} \mathrm{T}$ cell compartment (Fig. 3C, D). Similar results were also observed for total $\mathrm{T}$ cell frequencies, numbers and activation in blood and spleen (Fig. S3). These observations suggest a more robust, HLA-DR15-associated T cell proliferation and activation following EBV infection. 


\section{Reduced EBV-specific immune control in HLA-DR15-reconstituted huNSG}

In our huNSG model of EBV infection ( $10^{5}$ infectious particles), blood viral DNA loads are usually detectable at three weeks post infection [26]. Interestingly, we observed a higher EBV viral load at time of sacrifice in animals reconstituted with HLA-DR15 positive versus HLA-DR15 negative donors (Fig. 4A) or HLA-DR4 positive donors (Fig. 4B), even though their initial reconstitution was similar (Fig. S4A, B). It has previously been shown that $\mathrm{CD} 8^{+} \mathrm{T}$ cell expansion and blood viral load are positively correlated with disease severity in IM patients [8]. Indeed, we observed positive correlations between EBV viral loads in the blood and frequencies of activated CD8 ${ }^{+}$ T cells in the blood (Fig. 4C), as well as EBV viral loads in the spleen and frequencies of activated $\mathrm{CD}^{+} \mathrm{T}$ cells in the spleen (Fig. 4D). Similar correlations of EBV viral loads with total numbers of activated $\mathrm{CD}^{+} \mathrm{T}$ cells were also observed in blood and spleen (Fig. S4C, D). This data, together with increased frequencies (Fig. 2B to E) and activation (Fig. 3A, B) of $\mathrm{CD} 8^{+} \mathrm{T}$ cells, suggests a reduced $\mathrm{EBV}$-specific immune control despite significant $\mathrm{CD}^{+} \mathrm{T}$ cell expansion that is associated with HLA-DR15.

The humoral immune response has been challenging to study in the huNSG and other humanized mouse models. These animals lack normal lymph node development and have poor germinal center organization, thereby hampering B cell class switching and affinity maturation [26]. Upon measuring serum anti-EBV nuclear antigen 1 (EBNA1) immunoglobulin M (IgM), we were, however, able to find a fraction of EBVinfected animals positive for these antibodies (Fig. 4E). The humoral anti-EBNA1 IgM titer from animals with a humoral response above threshold correlated with blood EBV viral loads (Fig. 4F), however due to the infrequent IgM responses, we were not able to compare between HLA-DR15 positive and negative animals. Thus, EBV is less well 
immune controlled in the context of HLA-DR15; higher viral loads were observed despite elevated $\mathrm{CD} 8^{+} \mathrm{T}$ cell expansion.

Myelin antigen recognition, alloreactivity and lower specificity by HLA-DR15restricted T cells

EBNA1-specific $\mathrm{CD}^{+} \mathrm{T}$ cells have been previously shown to cross-react to myelin antigens [27]. We were therefore interested in examining if $\mathrm{CD}^{+} \mathrm{T}$ cells isolated from EBV-infected animals would cross-react to peptide pools spanning myelin basic protein (MBP) and myelin oligodendrocyte glycoprotein (MOG). These two myelin-derived MS autoantigens have been previously studied for their immunodominance in humans and/or encephalitogenic potential in animal models (reviewed in [28, 29]) and show comparable mathematically-predicted epitope binding affinity to HLA-DR15 and HLA-DR4 molecules [30]. Furthermore, immunodominant high avidity target peptides of MBP are known to be recognized in the context of both HLA-DR15 and HLA-DR4 $[30,31] . \mathrm{CD}^{+} \mathrm{T}$ cells from the splenocytes of EBV-infected animals were expanded before being stimulated with MBP, MOG or EBV peptide pools. Frequency of IFN $\gamma$ producing cells was then measured in the ELISpot assay. Interestingly, we observed that $\mathrm{CD}^{+} \mathrm{T}$ cells from nearly all HLA-DR15 and from a fraction of HLA-DR4 reconstituted animals produced IFN $\gamma$ in response to MBP stimulation (Fig. 5A, Fig. S5A). EBV derived peptide reactivity was more pronounced in a subset of HLA-DR4 reconstituted animals. These findings suggest MBP recognition by HLA-DR15 positive $\mathrm{CD} 4^{+} \mathrm{T}$ cells of EBV infected humanized mice.

Considering the essential role of T cells in the immune control of EBV infection [25] and our results suggesting that EBV might be less well controlled under HLADR15 restriction, we examined EBV infected $\mathrm{B}$ cell recognition of individual $\mathrm{CD}^{+} \mathrm{T}$ 
cell clones. For this purpose, $\mathrm{CD}^{+} \mathrm{T}$ cell clones were isolated from $\mathrm{EBV}$-infected, HLA-DR15 or HLA-DR4 reconstituted animals using bare lymphocyte syndrome lymphoblastoid cell lines (BLCLs; cells isolated from bare lymphocyte syndrome patients lacking MHC Class II expression) transfected with single MHC Class II molecules as targets. $\mathrm{CD}^{+} \mathrm{T}$ cells that produced IFN $\gamma$ in response to either HLADR15 ${ }^{+}$or HLA-DR4 ${ }^{+}$BLCLs were cloned (Fig. 5B). During the initial T cell clone screening for IFN $\gamma$ production via ELISA, we observed BLCL-restricted IFN $\gamma$ production in only $27 \%$ of HLA-DR15-restricted T cell clones, versus in $71 \%$ of HLADR4-restricted T cell clones tested (data not shown). Three HLA-DR15-restricted and two HLA-DR4-restricted CD4 ${ }^{+} \mathrm{T}$ cell clones were used in the assays.

The $\mathrm{CD} 4^{+} \mathrm{T}$ cell clones were incubated together with their HLA matched (auto) or mismatched (allo) BLCLs as targets (HLA-DR15-expressing or HLA-DR4expressing, depending on the genetic restriction of the $\mathrm{T}$ cell clone). Intracellular cytokine staining for IFN $\gamma$ (Fig. 5C), TNF $\alpha$ (Fig. 5D) and IL-2 (Fig. 5E) revealed stronger alloreactive responses from $\mathrm{CD} 4^{+} \mathrm{T}$ cell clones restricted by HLA-DR15. In trying to isolate the specificity of the responses that we observed, the responses towards HLA mismatched BLCLs were subtracted from the recognition of HLA matched targets (Fig. 5C to E, lower panels). In contrast, expression of the transcription factors T-bet and EOMES by the investigated $\mathrm{T}$ cell clones was not largely altered by the different stimulations (Fig. S5C, D).

To test their cytotoxic ability, the $\mathrm{CD}^{+} \mathrm{T}$ cell clones were also incubated together with their HLA matched or mismatched BLCLs as targets. While at 6 hours of incubation (Fig. 6A), the pattern is less evident, at 18 hours of incubation (Fig. 8B), HLA-DR4-restricted $\mathrm{CD}^{+} \mathrm{T}$ cell clones killed their targets with higher specificity as HLA-DR15-restricted $\mathrm{CD}^{+} \mathrm{T}$ cell clones showed higher alloreactive responses. In 
addition, degranulation assessed by CD107a surface expression and the cytotoxic granule marker granzyme B were used to gain insight into the cytolytic potential of the T cell clones. Interestingly, HLA-DR4-restricted $\mathrm{CD}^{+}{ }^{+} \mathrm{T}$ cell clones degranulated very specifically, whilst HLA-DR15-restricted $\mathrm{CD}^{+} \mathrm{T}$ cell clones not only degranulated less, but also demonstrated significant degranulation to the allogeneic target (Fig. 6C). HLA-DR15-restricted clones also displayed high granzyme B expression when incubated with both HLA matched and mismatched targets, whilst HLA-DR4-restricted clones seemed to up-regulate granzyme B only upon recognition of the HLA matched target (Fig. 6D). This is also evident when responses towards HLA mismatched BLCLs were subtracted from the recognition of HLA matched targets (Fig. 6A to D, lower panels) and further highlight above-mentioned results.

These data provide evidence for $\mathrm{CD}^{+}{ }^{+} \mathrm{T}$ cell cross-reactivity to myelin antigens. In addition, weaker HLA-DR15-restricted $\mathrm{CD}^{+} \mathrm{T}$ cell responses against EBVtransformed B cells, but also inflammatory responses that show tendencies towards alloreactivity. Thus, the HLA-DR15 genetic risk factor may stimulate EBV-specific $\mathrm{CD}^{+} \mathrm{T}$ cell responses that recognize allogeneic target cells as well as myelin antigens, and that provide insufficient help to $\mathrm{CD}^{+} \mathrm{T}$ cells in order to efficiently control EBV infection. This could lead to both IM-like lymphocytosis and promote cross-reactive autoimmune $\mathrm{CD} 4^{+} \mathrm{T}$ cell stimulation. 


\section{DISCUSSION}

Evidence suggests dysregulated adaptive immunity to be at the core of MS [1]. HLA class II molecules, such as HLA-DR15, are expressed on antigen presenting cells. They present peptides derived from self or exogenous proteins to $\mathrm{CD} 4^{+} \mathrm{T}$ cells, which then support and strengthen cellular and humoral immune responses [32]. Indeed, in addition to the importance of $\mathrm{CD}^{+}{ }^{+} \mathrm{T}$ cells in MS pathogenesis, evidence from CNS-infiltrating immune cells in patients and B cell-depleting therapies suggests additional roles for $\mathrm{CD}^{+} \mathrm{T}$ cells and $\mathrm{B}$ cells in the disease $[33,34]$, supported by or supporting autoimmune $\mathrm{CD}^{+} \mathrm{T}$ cell responses.

In vivo EBV infection of huNSG mice has allowed us to study the interaction between the main genetic risk factor for MS, HLA-DR15, with the main environmental risk factor, EBV-induced immune responses [4]. Similar to MS patients, we observed elevated EBV induced $\mathrm{T}$ cell responses in huNSG mice with HLA-DR15 positive immune compartments $[27,35]$. These seemed to result from a higher constitutive $\mathrm{T}$ cell activation and increased $\mathrm{CD} 8^{+} \mathrm{T}$ cell expansion due to less well controlled viral loads in connection with this particular MHC class II molecule. Furthermore, we observed $\mathrm{CD}^{+} \mathrm{T}$ cell cross-reactivity to the MS autoantigen MBP and $\mathrm{CD}^{+} \mathrm{T}$ cell clones isolated from these EBV-infected huNSG mice that were selected for HLADR15-restricted EBV transformed B cell (LCL) recognition displayed diminished immune recognition of EBV-infected B cells and higher cross-reactivity to HLA-DR mismatched targets. These findings point to both diminished immune control of EBV and its proinflammatory effects, as well as increased cross-reactivity of the $\mathrm{CD}^{+}{ }^{+} \mathrm{T}$ cell compartment that is more activated by the poorly controlled EBV infection in the context of HLA-DR15. In this way, EBV-induced immune responses could synergize with HLA-DR15 to enhance MS. 
Indeed, cross-reactivity with molecular mimicry between EBV and myelinderived autoantigens has been proposed previously. Primarily, EBNA1 and lytic EBV antigen-specific antibodies, in addition to $\mathrm{CD}^{+} \mathrm{T}$ cell responses, are elevated in patients with MS and sometimes enriched in the CNS [19, 27, 35-39]. Some of these have indeed been suggested to cross-react with CNS autoantigens, like myelin basic protein, heterogeneous nuclear ribonucleoprotein L, septin-9 or anoctamin 2 [27, 3942]. This cross-reactivity could amplify $\mathrm{T}$ cell and antibody responses against select EBV gene products, including EBNA1, BFRF3 and BRRF2 [27, 39, 41], as well as lead to the local restimulation in the CNS to promote MS-associated lesion formation. Moreover, EBV might induce homing capacities in the respective cross-reactive lymphocyte populations to guide them to the CNS. In line with this, the chemokine CXCL10 was shown to be expressed by EBV-transformed cells, attracting EBVspecific T cells [43] and was also found in the CSF of MS patients [44].

Both B and T cell homing of cross-reactive specificities would however be a prerequisite of focusing the resulting autoimmunity on the CNS. Along these lines the $\alpha 4 \beta 1$ integrin has been found to be essential for CNS homing of $\mathrm{T}$ cells [45]. In addition, the chemokine receptors CXCR3, CCR5, CCR6 and CCR7 have been implicated in brain infiltration of T cells $[44,46,47]$ and should be investigated for presence of cross-reactive lymphocyte populations. Cross-reactive T and B cells might then re-stimulate each other in the CNS of patients with MS to promote relapsingremitting and progressive courses of the disease.

Such T cell stimulatory capacity of B cells in MS brains could be further augmented by EBV infection that increases co-stimulatory activity for $\mathrm{T}$ cell stimulation [48]. Along these lines, EBV-infected B cells have been detected in the meninges and lesions in the brains of MS patients [49], but these findings are heavily 
debated [50]. Considering EBV biology and life cycle, B cell stimulation of $\mathrm{T}$ cell responses in secondary lymphoid organs might be of great importance. As already mentioned, EBV establishes a life-long infection in memory B cells and by doing so, modulates their differentiation and function, and promotes their survival [51]. Indeed, memory B cells have recently been shown to mediate the activation of autoreactive $\mathrm{CD}^{+}{ }^{+} \mathrm{T}$ cells [52]. It is plausible that EBV infects autoreactive B cells, or B cells that might present antigen to pathogenic, cross-reactive $\mathrm{T}$ cells over a long period of time. In addition, in genetically susceptible hosts, acute immune pathologies like IM could serve to decrease the threshold of $\mathrm{T}$ cell activation, facilitating pathogenic B-T cell interactions. The exaggerated EBV-specific T cell expansion during IM could expand $\mathrm{T}$ cells that have been selected in the thymus by self-peptides and will only undergo full activation under acute EBV infection to remain as memory $\mathrm{T}$ cells.

Indeed, B cell depleting therapies, which leave oligoclonal antibody production in the CNS and systemic antibody production by long-lived plasma cells in the bone marrow usually unaffected, have demonstrated beneficial effects in MS patients [34, 53]. Furthermore, adoptive transfer of EBV-specific in vitro-expanded T cell lines into patients with MS, even at advanced disease, has demonstrated some encouraging results [54]. These T cells might eliminate an EBV-infected B cell compartment that stimulates autoreactive $\mathrm{T}$ cell responses, possibly even in the brain. Thus, inefficient immune control of EBV-infected B cells in the context of HLA-DR15 might allow for both priming of cross-reactive $\mathrm{T}$ cell responses and their local restimulation by EBVinfected B cells to propagate autoimmunity in the CNS of patients with MS. 


\section{MATERIALS \& METHODS}

\section{Animal work}

NOD-scid IL2 receptor $\gamma$-chain-deficient (NSG) animals with or without an HLA-A2 (NSG-A2) heavy chain transgene (Jackson Laboratory, Bar Harbor, Maine, USA) were maintained under specific pathogen-free conditions at the Institute of Experimental Immunology, University of Zürich, Switzerland. Newborn pups (1-5 days old) were sublethally irradiated with $1 \mathrm{~Gy}$ and 5 to 7 hours later, intrahepatically injected with around 1.5-3 x 10 $0^{5}$ human fetal liver (Advanced Bioscience Resources)-derived and HLA typed $\mathrm{CD} 34^{+}$hematopoietic progenitor cells. $\mathrm{CD} 34^{+}$cells were isolated by magnetic bead separation based on manufacturer's instructions (Miltenyi Biotech) and frozen in liquid nitrogen. After twelve weeks, peripheral blood was collected from the tail vein and analyzed for human $\mathrm{CD}_{4} 5^{+}, \mathrm{CD}^{+}, \mathrm{CD}^{+}, \mathrm{CD}^{+}$and $\mathrm{HLA}-\mathrm{DR}^{+}$cells by flow cytometry. Both female and male animals 3 to 5 months old and engrafted with human immune cells were intraperitoneally injected with $10^{5}$ EBV Raji infectious units (RIU) or PBS and monitored for up to 6 weeks. Animals used in each experiment were reconstituted from a single donor. NSG-A2 animals were transplanted with HLA-A2 positive CD34+ cells.

\section{$E B V$}

EBV strain B95-8 was produced in human embryonic kidney HEK293 cells (ATCC) containing a GFP-encoding wild type EBV BACmid (p2089; kind gift from H.-J. Delecluse) [55]. Virus concentrates were titrated on Raji cells (ATCC) and GFPexpressing cells were analysed two days later by flow cytometry (FACSCanto II or LSR Fortessa, BD Biosciences) to determine the EBV RIU. 


\section{Enzyme-linked Immunosorbent assay (ELISA)}

IFN $\gamma$ in $\mathrm{T}$ cell clone supernatants was measured by the human IFN $\gamma$ ELISA development kit (Mabtech AB) according to the manufacturer's instructions. EBNA1 IgM in huNSG mouse serum was measured by the Epstein-Barr virus EBNA1 IgM ELISA (IBL International) following the manufacturer's instructions. The threshold to determine positive $\operatorname{IgM}$ values was set by the mean $+2 \mathrm{x}$ standard deviation of PBS animals.

\section{Enzyme-linked Immunospot assay (ELISpot)}

$\mathrm{CD}^{+} \mathrm{T}$ cells were isolated from the splenocytes of HLA-DR15 or HLA-DR4 reconstituted, EBV-infected animals (negative magnetic bead separation, Miltenyi Biotec) and expanded by seeding on irradiated allogeneic LCLs as feeder cells (45Gy) with $1 \mu \mathrm{g} / \mathrm{ml}$ PHA-L (Merck Millipore) and 20 U/ml IL-2 (Peprotech). Fresh IL-2 was added three times per week.

IFN $\gamma$-producing $\mathrm{CD}^{+}{ }^{+} \mathrm{T}$ cells were assayed by the human IFN $\gamma$ ELISpot ${ }^{\text {BASIC }}$ kit (ALP) (Mabtech AB) according to the manufacturer's instructions. On day 15 of expansion, $\mathrm{CD}^{+} \mathrm{T}$ cells were seeded on pre-coated 96 well plates (MultiScreen Filter Plates, Merck Millipore) at 2.7-5 x 10 4 per well with $2 \times 10^{4}$ HLA-matched BLCLs (HLA-DR15 or HLA-DR4-transfected). Myelin-basic protein (MBP), myelin oligodendrocyte glycoprotein (MOG) and EBV peptide pools (kind gift from R. Martin, unpublished) were added at $1 \mu \mathrm{M}$ concentration for each peptide in the pool (DMSO concentration $<0.5 \%$ ) and incubated with the cells for 28 hours at $37^{\circ} \mathrm{C}$. CD $4^{+} \mathrm{T}$ cells alone were used as negative control and $\mathrm{CD} 4^{+} \mathrm{T}$ cells stimulated with PMA/ionomycin as positive control. Wells were counted with the AID ELISpot reader and software (Autoimmun Diagnostika GmbH). 


\section{T cell cloning}

$\mathrm{CD}^{+} \mathrm{T}$ cells were isolated from the splenocytes of EBV-infected animals (magnetic bead separation, Miltenyi Biotec) and stimulated with transgenic HLA-matched bare lymphocyte syndrome lymphoblastoid cell lines (BLCLs; HLA-DR15 or HLA-DR4transfected) for 3-4 hours at $37^{\circ} \mathrm{C}$. IFN $\gamma$-producing cells were then selected with the IFN $\gamma$ Secretion Assay - Detection kit (PE), human (Miltenyi Biotech) and diluted into 96-well plates pre-filled with irradiated PBMC feeder cells and HLA matched BLCLs (20Gy and 60Gy, respectively). IL-2 (Peprotech) was added two days later and subsequently twice a week at 100-125 U/ml. Two to four weeks later, growing clones were screened with the Human IFN $\gamma$ ELISA development kit (Mabtech AB) and IFN $\gamma$ producing clones were placed into culture. $\mathrm{CD}^{+} \mathrm{T}$ cell clones were fed every two to three weeks with irradiated PBMC feeder cells and HLA matched BLCLs, together with $100-125 \mathrm{U} / \mathrm{ml}$ of IL-2.

For T cell clone killing assays, BLCLs were labelled with PKH26 (SigmaAldrich). $\mathrm{CD}^{+} \mathrm{T}$ cell clones were then incubated alone, or with labelled matched or mismatched BLCLs at 5:1 ratio for 6 or 18 hours. TO-PRO-3 dye (Life Technologies) was used as a dead cell indicator. For degranulation experiments, $\mathrm{CD} 4^{+} \mathrm{T}$ cell clones were incubated alone, or with matched or mismatched BLCLs at 1:1 ratio and stained for CD107a (BD Biosciences). Cells were incubated for 2 hours before the addition of Brefeldin A (Sigma-Aldrich) and incubated for further 6 hours. For transcription factor expression experiments, $\mathrm{CD} 4^{+} \mathrm{T}$ cell clones were incubated alone, or with matched or mismatched BLCLs at 1:1 ratio for 8 hours. 


\section{Flow cytometry}

Whole blood was lysed with ACK lysing buffer (Gibco) and washed to obtain peripheral blood mononuclear cells (PBMCs). Spleens were physically dissociated through a $70 \mu \mathrm{M}$ strainer and layered on Ficoll-Paque (GE Healthcare) for the separation of mononuclear cells by density gradient centrifugation. Total numbers of leukocytes were calculated from the white blood cell count measured by Beckman Coulter AcT diff Analyzer. PBMCs, splenocytes or $\mathrm{CD}^{+} \mathrm{T}$ cell clones were stained with extracellular antibodies for 20 minutes at $4^{\circ} \mathrm{C}$, washed and resuspended either in PBS or fixed in $1 \%$ paraformaldehyde (PFA). For intracellular staining, extracellularstained samples were processed with the Cytofix/Cytoperm Fixation/Permeabilization Kit (BD Biosciences) according to manufacturer's instructions. For intranuclear staining, extracellular-stained samples were processed with the Foxp3/Transcription Factor Staining Buffer Set (eBioscience, Thermo Fisher Scientific) following the manufacturer's instructions. Live/dead Near IR (Invitrogen) or Zombie NIR (Biolegend) was used for live cell separation.

Antibody clones used in this study: CD45 (HI30, Biolegend), CD3 (OKT3, UCHT1, Biolegend), CD4 (OKT4, RPA-T4, Biolegend), CD8 (SK1, Biolegend), CD19 (HIB19, Biolegend), HLA-DR (G46-6, BD Biosciences, L243, Biolegend), Eomes (WD1928, eBioscience), T-bet (4B10, eBioscience), IFN $\gamma$ (4S.B3, eBioscience), IL-2 (MQ117H12, eBioscience), TNF $\alpha$ (Mab11, BD Biosciences), Granzyme B (GB11, BD Biosciences), CD107a (H4A3, BD Biosciences). 
Samples were acquired on the FACSCanto II or LSR Fortessa (BD Biosciences) and analysed using the Flowjo Software (Becton, Dickinson \& Company) following Cossarizza and colleagues [56] whenever possible.

\section{Viral load quantification}

Splenic tissue was processed for DNA isolation using the DNeasy Blood and Tissue Kit (QIAGEN) and total DNA from whole blood was extracted using the NucliSENS EasyMAG System (bioMérieux), following the manufacturer's instructions. TaqMan real-time PCR (Applied Biosystems) was used to quantify EBV DNA, with modified primers for the BamH1 W fragment (5'-CTTCTCAGTCCAGCGCGTTT-3' and 5'CAGTGGTCCCCCTCCCTAGA-3') and a fluorogenic probe (5'-FAM CGTAAGCCAGACAGCAGCCAATTGTCAG-TAMRA-3'). All samples were analyzed in duplicates.

\section{HLA typing}

DNA was extracted using the QIAGEN GmbH reagent, according to the manufacturer's instructions. Commercial HLA kits (Fujirebio Diagnostics Inc.) were used to identify the HLA alleles using a PCR sequence-specific oligonucleotide reverse assay. Data analysis was performed using the LIPA Interpretation Software (Fujirebio Diagnostics Inc.).

\section{Statistical analysis}

Statistical analysis was performed with the GraphPad Prism Software. The MannWhitney U test was used to analyze unpaired data with a non-Gaussian distribution. Correlations on non-Gaussian distributed data were analyzed using the Spearman's 
rank correlation coefficient. The D'Agostino-Pearson omnibus normality test was used to determine normality of data. A p value $<0.05$ was considered statistically significant.

\section{Ethics statement}

All animal experimentation was approved by the cantonal veterinary office of Zürich, Switzerland (protocols 148/2011, 209/2014 and 159/17) and conducted according to the Swiss Animal Welfare Act, Tierschutzgesetz (TSchG). All human sample studies were approved by the cantonal ethical committee of Zürich, Switzerland, and informed consent of all participating subjects has been obtained (protocols KEK-StV-Nr.19/08 and 2019-00837). 


\section{ACKNOWLEDGMENTS}

This research was supported by supported by Cancer Research Switzerland (KFS-4091-

02-2017), KFSP-Precision ${ }^{\mathrm{MS}}$ of the University of Zurich, the Vontobel Foundation, the Baugarten Foundation, the Sobek Foundation, the Swiss Vaccine Research Institute, the Swiss MS Society, Roche and the Swiss National Science Foundation (310030B_182827 and CRSII5_180323).

\section{CONFLICT OF INTEREST}

The authors declare no commercial or financial conflict of interest.

\section{DATA AVAILABILITY STATEMENT}

The data that support the findings of this study are available from the corresponding author upon reasonable request. 


\section{REFERENCES}

1 Sospedra, M. and Martin, R., Immunology of multiple sclerosis. Annu Rev Immunol 2005. 23: 683-747.

2 Sawcer, S., Hellenthal, G., Pirinen, M., Spencer, C. C. A., Patsopoulos, N. A., Moutsianas, L., Dilthey, A. et al., Genetic risk and a primary role for cellmediated immune mechanisms in multiple sclerosis. Nature 2011. 476: 214219.

3 Beecham, A. H., Patsopoulos, N. A., Xifara, D. K., Davis, M. F., Kemppinen, A., Cotsapas, C., Shah, T. S. et al., Analysis of immune-related loci identifies 48 new susceptibility variants for multiple sclerosis. Nature Genetics 2013. 45: 1353-+.

4 Olsson, T., Barcellos, L. F. and Alfredsson, L., Interactions between genetic, lifestyle and environmental risk factors for multiple sclerosis. Nat Rev Neurol 2017. 13: 25-36.

5 Nielsen, T. R., Rostgaard, K., Askling, J., Steffensen, R., Oturai, A., Jersild, C., Koch-Henriksen, N. et al., Effects of infectious mononucleosis and HLADRB1*15 in multiple sclerosis. Mult Scler 2009. 15: 431-436.

6 Niederman, J. C., Infectious mononucleosis: observations on transmission. Yale J Biol Med 1982. 55: 259-264.

7 Babcock, G. J., Decker, L. L., Volk, M. and Thorley-Lawson, D. A., EBV persistence in memory B cells in vivo. Immunity 1998. 9: 395-404.

8 Balfour, H. H., Jr., Odumade, O. A., Schmeling, D. O., Mullan, B. D., Ed, J. A., Knight, J. A., Vezina, H. E. et al., Behavioral, virologic, and immunologic factors associated with acquisition and severity of primary Epstein-Barr virus infection in university students. J Infect Dis 2013. 207: 8088.

9 Odumade, O. A., Knight, J. A., Schmeling, D. O., Masopust, D., Balfour, H. H., Jr. and Hogquist, K. A., Primary Epstein-Barr virus infection does not erode preexisting $\mathrm{CD}^{+} \mathrm{T}$ cell memory in humans. $J$ Exp Med 2012. 209: 471478.

10 Silins, S. L., Sherritt, M. A., Silleri, J. M., Cross, S. M., Elliott, S. L., Bharadwaj, M., Le, T. T. et al., Asymptomatic primary Epstein-Barr virus 
infection occurs in the absence of blood T-cell repertoire perturbations despite high levels of systemic viral load. Blood 2001. 98: 3739-3744.

11 Abbott, R. J., Pachnio, A., Pedroza-Pacheco, I., Leese, A. M., Begum, J., Long, H. M., Croom-Carter, D. et al., Asymptomatic Primary Infection with Epstein-Barr Virus: Observations on Young Adult Cases. J Virol 2017. 91.

12 Leibowitz, U., Antonovsky, A., Medalie, J. M., Smith, H. A., Halpern, L. and Alter, M., Epidemiological Study of Multiple Sclerosis in Israel .2. Multiple Sclerosis and Level of Sanitation. Journal of Neurology Neurosurgery and Psychiatry 1966. 29: 60-+.

13 Kurtzke, J. F., Epidemiologic evidence for multiple sclerosis as an infection. Clin Microbiol Rev 1993. 6: 382-427.

14 Alotaibi, S., Kennedy, J., Tellier, R., Stephens, D. and Banwell, B., EpsteinBarr virus in pediatric multiple sclerosis. JAMA 2004. 291: 1875-1879.

15 Pohl, D., Krone, B., Rostasy, K., Kahler, E., Brunner, E., Lehnert, M., Wagner, H. J. et al., High seroprevalence of Epstein-Barr virus in children with multiple sclerosis. Neurology 2006. 67: 2063-2065.

16 Levin, L. I., Munger, K. L., O'Reilly, E. J., Falk, K. I. and Ascherio, A., Primary Infection with the Epstein-Barr Virus and Risk of Multiple Sclerosis. Annals of Neurology 2010. 67: 824-830.

17 Thacker, E. L., Mirzaei, F. and Ascherio, A., Infectious mononucleosis and risk for multiple sclerosis: A meta-analysis. Annals of Neurology 2006. 59: 499503.

18 Handel, A. E., Williamson, A. J., Disanto, G., Handunnetthi, L., Giovannoni, G. and Ramagopalan, S. V., An Updated Meta-Analysis of Risk of Multiple Sclerosis following Infectious Mononucleosis. Plos One 2010. 5.

19 Ascherio, A., Munger, K. L., Lennette, E. T., Spiegelman, D., Hernan, M. A., Olek, M. J., Hankinson, S. E. et al., Epstein-Barr virus antibodies and risk of multiple sclerosis - A prospective study. Jama-Journal of the American Medical Association 2001. 286: 3083-3088.

20 Levin, L. I., Munger, K. L., Rubertone, M. V., Peck, C. A., Lennette, E. T., Spiegelman, D. and Ascherio, A., Temporal relationship between elevation of Epstein-Barr virus antibody titers and initial onset of neurological symptoms in multiple sclerosis. Jama-Journal of the American Medical Association 2005. 293: 2496-2500. 
21 Zhou, Y., Zhu, G., Charlesworth, J. C., Simpson, S., Rubicz, R., Goring, H. H. H., Patsopoulos, N. A. et al., Genetic loci for Epstein-Barr virus nuclear antigen-1 are associated with risk of multiple sclerosis. Multiple Sclerosis Journal 2016. 22: 1655-1664.

22 Sundstrom, P., Nystrom, M., Ruuth, K. and Lundgren, E., Antibodies to specific EBNA-1 domains and HLA DRB1*1501 interact as risk factors for multiple sclerosis. Journal of Neuroimmunology 2009. 215: 102-107.

23 Fugger, L. and Svejgaard, A., Association of MHC and rheumatoid arthritis. HLA-DR4 and rheumatoid arthritis: studies in mice and men. Arthritis Res 2000. 2: 208-211.

24 Noble, J. A. and Valdes, A. M., Genetics of the HLA region in the prediction of type 1 diabetes. Curr Diab Rep 2011. 11: 533-542.

25 Strowig, T., Gurer, C., Ploss, A., Liu, Y. F., Arrey, F., Sashihara, J., Koo, G. et al., Priming of protective T cell responses against virus-induced tumors in mice with human immune system components. J Exp Med 2009. 206: 14231434.

26 Gujer, C., Chatterjee, B., Landtwing, V., Raykova, A., McHugh, D. and Münz, C., Animal models of Epstein Barr virus infection. Curr Opin Virol 2015. 13: 6-10.

27 Lunemann, J. D., Jelcic, I., Roberts, S., Lutterotti, A., Tackenberg, B., Martin, R. and Münz, C., EBNA1-specific T cells from patients with multiple sclerosis cross react with myelin antigens and co-produce IFN-gamma and IL2. J Exp Med 2008. 205: 1763-1773.

28 Meinl, E. and Hohlfeld, R., Immunopathogenesis of multiple sclerosis: MBP and beyond. Clin Exp Immunol 2002. 128: 395-397.

29 Hohlfeld, R., Dornmair, K., Meinl, E. and Wekerle, H., The search for the target antigens of multiple sclerosis, part 1: autoreactive CD4 ${ }^{+} \mathrm{T}$ lymphocytes as pathogenic effectors and therapeutic targets. Lancet Neurol 2016. 15: 198209.

30 Bielekova, B., Sung, M. H., Kadom, N., Simon, R., McFarland, H. and Martin, R., Expansion and functional relevance of high-avidity myelin-specific $\mathrm{CD}^{+}{ }^{+} \mathrm{T}$ cells in multiple sclerosis. J Immunol 2004. 172: 3893-3904.

31 Muraro, P. A., Vergelli, M., Kalbus, M., Banks, D. E., Nagle, J. W., Tranquill, L. R., Nepom, G. T. et al., Immunodominance of a low-affinity 
major histocompatibility complex-binding myelin basic protein epitope (residues 111-129) in HLA-DR4 (B1*0401) subjects is associated with a restricted T cell receptor repertoire. J Clin Invest 1997. 100: 339-349.

32 Roche, P. A. and Furuta, K., The ins and outs of MHC class II-mediated antigen processing and presentation. Nat Rev Immunol 2015. 15: 203-216.

33 Babbe, H., Roers, A., Waisman, A., Lassmann, H., Goebels, N., Hohlfeld, R., Friese, M. et al., Clonal expansions of CD8(+) T cells dominate the T cell infiltrate in active multiple sclerosis lesions as shown by micromanipulation and single cell polymerase chain reaction. J Exp Med 2000. 192: 393-404.

34 Hauser, S. L., Waubant, E., Arnold, D. L., Vollmer, T., Antel, J., Fox, R. J., Bar-Or, A. et al., B-cell depletion with rituximab in relapsing-remitting multiple sclerosis. N Engl J Med 2008. 358: 676-688.

35 Angelini, D. F., Serafini, B., Piras, E., Severa, M., Coccia, E. M., Rosicarelli, B., Ruggieri, S. et al., Increased CD8+ T cell response to Epstein-Barr virus lytic antigens in the active phase of multiple sclerosis. PLoS Pathog 2013. 9: e1003220.

36 Lunemann, J. D., Huppke, P., Roberts, S., Bruck, W., Gartner, J. and Münz, C., Broadened and elevated humoral immune response to EBNA1 in pediatric multiple sclerosis. Neurology 2008. 71: 1033-1035.

37 Lunemann, J. D., Tintore, M., Messmer, B., Strowig, T., Rovira, A., Perkal, H., Caballero, E. et al., Elevated Epstein-Barr virus-encoded nuclear antigen1 immune responses predict conversion to multiple sclerosis. Ann Neurol 2010. 67: 159-169.

38 Erdur, H., Scholz, V., Streitz, M., Hammer, M., Meisel, C., Schonemann, C., Wandinger, K. P. et al., EBNA1 antigen-specific $\mathrm{CD}^{+} \mathrm{T}$ cells in cerebrospinal fluid of patients with multiple sclerosis. J Neuroimmunol 2016. 294: 14-17.

39 Dooley, M. M., de Gannes, S. L., Fu, K. A. and Lindsey, J. W., The increased antibody response to Epstein-Barr virus in multiple sclerosis is restricted to selected virus proteins. J Neuroimmunol 2016. 299: 147-151.

40 Mameli, G., Cossu, D., Cocco, E., Masala, S., Frau, J., Marrosu, M. G. and Sechi, L. A., Epstein-Barr virus and Mycobacterium avium subsp. paratuberculosis peptides are cross recognized by anti-myelin basic protein antibodies in multiple sclerosis patients. J Neuroimmunol 2014. 270: 51-55. 
41 Lindsey, J. W., Antibodies to the Epstein-Barr virus proteins BFRF3 and BRRF2 cross-react with human proteins. J Neuroimmunol 2017. 310: 131-134.

42 Tengvall, K., Huang, J., Hellstrom, C., Kammer, P., Bistrom, M., Ayoglu, B., Lima Bomfim, I. et al., Molecular mimicry between Anoctamin 2 and Epstein-Barr virus nuclear antigen 1 associates with multiple sclerosis risk. Proc Natl Acad Sci U S A 2019. 116: 16955-16960.

43 White, R. E., Ramer, P. C., Naresh, K. N., Meixlsperger, S., Pinaud, L., Rooney, C., Savoldo, B. et al., EBNA3B-deficient EBV promotes B cell lymphomagenesis in humanized mice and is found in human tumors. J Clin Invest 2012. 122: 1487-1502.

44 Sorensen, T. L., Tani, M., Jensen, J., Pierce, V., Lucchinetti, C., Folcik, V. A., Qin, S. et al., Expression of specific chemokines and chemokine receptors in the central nervous system of multiple sclerosis patients. J Clin Invest 1999. 103: $807-815$.

45 Engelhardt, B. and Ransohoff, R. M., Capture, crawl, cross: the T cell code to breach the blood-brain barriers. Trends Immunol 2012. 33: 579-589.

46 Balashov, K. E., Rottman, J. B., Weiner, H. L. and Hancock, W. W., CCR5 ${ }^{+}$ and $\mathrm{CXCR}^{+} \mathrm{T}$ cells are increased in multiple sclerosis and their ligands MIP1alpha and IP-10 are expressed in demyelinating brain lesions. Proc Natl Acad Sci U S A 1999. 96: 6873-6878.

47 Paroni, M., Maltese, V., De Simone, M., Ranzani, V., Larghi, P., Fenoglio, C., Pietroboni, A. M. et al., Recognition of viral and self-antigens by TH1 and TH1/TH17 central memory cells in patients with multiple sclerosis reveals distinct roles in immune surveillance and relapses. J Allergy Clin Immunol 2017. 140: 797-808.

48 Leung, C. S., Maurer, M. A., Meixlsperger, S., Lippmann, A., Cheong, C., Zuo, J., Haigh, T. A. et al., Robust T-cell stimulation by Epstein-Barr virustransformed B cells after antigen targeting to DEC-205. Blood 2013. 121: 15841594.

49 Serafini, B., Rosicarelli, B., Franciotta, D., Magliozzi, R., Reynolds, R., Cinque, P., Andreoni, L. et al., Dysregulated Epstein-Barr virus infection in the multiple sclerosis brain. J Exp Med 2007. 204: 2899-2912.

50 Lassmann, H., Niedobitek, G., Aloisi, F., Middeldorp, J. M. and NeuroproMiSe, E. B. V. W. G., Epstein-Barr virus in the multiple sclerosis 
brain: a controversial issue--report on a focused workshop held in the Centre for Brain Research of the Medical University of Vienna, Austria. Brain 2011. 134: $2772-2786$.

51 Thorley-Lawson, D. A., Epstein-Barr virus: exploiting the immune system. Nat Rev Immunol 2001. 1: 75-82.

52 Jelcic, I., Al Nimer, F., Wang, J., Lentsch, V., Planas, R., Jelcic, I., Madjovski, A. et al., Memory B Cells Activate Brain-Homing, Autoreactive $\mathrm{CD}^{+}$T Cells in Multiple Sclerosis. Cell 2018. 175: 85-100 e123.

53 Hauser, S. L., Bar-Or, A., Comi, G., Giovannoni, G., Hartung, H. P., Hemmer, B., Lublin, F. et al., Ocrelizumab versus Interferon Beta-1a in Relapsing Multiple Sclerosis. N Engl J Med 2017. 376: 221-234.

54 Pender, M. P., Csurhes, P. A., Smith, C., Douglas, N. L., Neller, M. A., Matthews, K. K., Beagley, L. et al., Epstein-Barr virus-specific T cell therapy for progressive multiple sclerosis. JCI Insight 2018. 3.

55 Delecluse, H. J., Hilsendegen, T., Pich, D., Zeidler, R. and Hammerschmidt, W., Propagation and recovery of intact, infectious Epstein-Barr virus from prokaryotic to human cells. Proc Natl Acad Sci U S A 1998. 95: 8245-8250.

56 Cossarizza, A., Chang, H. D., Radbruch, A., Acs, A., Adam, D., AdamKlages, S., Agace, W. W. et al., Guidelines for the use of flow cytometry and cell sorting in immunological studies (second edition). European Journal of Immunology 2019. 49: 1457-1973. 


\section{FIGURE LEGENDS}

\section{Fig. 1: Higher T cell activation in HLA-DR15 ${ }^{+}$donor reconstituted huNSG mice.}

Three months post reconstitution, animals were bled and analyzed for reconstitution of human immune system components in peripheral blood. Data was stratified into animals reconstituted with HLA-DR15 negative(DR15'), HLA-DR15 positive (DR15 ${ }^{+}$) (A) and HLA-DR4 positive (DR4 ${ }^{+}$), HLA-DR15 positive (DR15 ${ }^{+}$DR4 $\left.4^{-}\right)$(B) donors and collected by flow cytometry. T cell activation was analyzed by positive staining of HLA-DR (DR). Data shown are combined from $>96$ donors ( $\mathrm{n}$ of animals $=3579$, $\mathrm{CD}^{+}$T cell activation $\left.\mathrm{n}=2991\right)(\mathrm{A})$ and 51 donors $\left(\mathrm{n}\right.$ of animals $=1230, \mathrm{CD}^{+} \mathrm{T}$ cell activation $\mathrm{n}=1135)(\mathbf{B}) . * p<0.05, * * * p<0.001, * * * * p<0.0001$, significant comparisons are indicated and significance is based on the Mann-Whitney U test. Each symbol indicates one animal (mean \pm SEM).

Fig. 2: EBV-infected HLA-DR15 ${ }^{+}$reconstituted mice have higher frequencies of CD8 $^{+} \mathbf{T}$ cells. Schematic depiction of analysed EBV infection experiments. After 3-5 months of human immune compartment reconstitution, animals were injected with $10^{5}$ EBV infectious units or PBS intraperitoneally and monitored for 4-6 weeks by visual examination, weight measurements and flow cytometry (A). At time of sacrifice (4-6 weeks post infection), frequencies of $\mathrm{CD}^{+} \mathrm{T}$ cells in blood and spleen $(\mathbf{B}, \mathbf{C})$, total numbers of $\mathrm{CD}^{+} \mathrm{T}$ cells in blood and spleen $(\mathbf{D}, \mathbf{E})$, frequencies of $\mathrm{CD}^{+} \mathrm{T}$ cells in blood and spleen $(\mathbf{F}, \mathbf{G})$, and total numbers of $\mathrm{CD}^{+} \mathrm{T}$ cells in blood and spleen $(\mathbf{H}, \mathbf{I})$, respectively, were analysed and stratified into animals reconstituted with HLA-DR15 negative (DR15') and HLA-DR15 positive (DR15') donors. Data shown are combined from 11 to 24 experiments and contain 19-65 animals per group. $* p<0.05, * * p<$ 
0.01, significant comparisons are indicated and significance is based on the MannWhitney U test. Each symbol indicates one animal (mean \pm SEM).

Fig. 3: EBV-infected HLA-DR15 ${ }^{+}$reconstituted mice have higher numbers of activated $\mathrm{CD8}^{+} \mathbf{T}$ cells. As indicated, animals were injected with $10^{5} \mathrm{EBV}$ infectious units or PBS intraperitoneally. At time of sacrifice (4-6 weeks post infection), total numbers of activated $\mathrm{CD} 8^{+} \mathrm{T}$ cells $(\mathbf{A}, \mathbf{B})$ and activated $\mathrm{CD} 4^{+} \mathrm{T}$ cells $(\mathbf{C}, \mathbf{D})$ in blood and spleen, respectively, were analysed and stratified into animals reconstituted with HLA-DR15 negative (DR15) and HLA-DR15 positive $\left(\mathrm{DR} 15^{+}\right)$donors. T cell activation was analyzed by positive staining of HLA-DR by flow cytometry. Data shown are combined from 11 to 13 experiments and contain 19-32 animals per group. $* p<0.05, * * p<0.01$, significant comparisons are indicated and significance is based on the Mann-Whitney U test. Each symbol indicates one animal (mean $\pm \mathrm{SEM}$ ).

Fig. 4: EBV viral loads in huNSG mice correlate with activated $\mathrm{CD8}^{+} \mathrm{T}$ cells and humoral IgM responses and are higher in HLA-DR15 ${ }^{+}$reconstituted animals. Blood EBV viral loads at time of sacrifice (4-6 weeks post infection with $10^{5} \mathrm{EBV}$ infectious units) of animals reconstituted with HLA-DR15 positive (DR15 ${ }^{+}$, HLADR15 negative (DR15 $)(\mathrm{n}=42$ and 70 , respectively) $(\mathbf{A})$, HLA-DR15 positive DR4 negative (DR15 $\left.{ }^{+} \mathrm{DR} 4^{-}\right)$and HLA-DR4 positive $\left(\mathrm{DR} 4^{+}\right)(\mathrm{n}=38$ and 22, respectively) (B) donors, measured by TaqMan real-time PCR. Red lines depict the median and significance is based on the Mann-Whitney U test (A, B). (C) Frequencies of activated $\mathrm{CD}^{+} \mathrm{T}$ cells in blood were plotted relative to blood EBV viral loads $(\mathrm{n}=56)$. (D) Frequencies of activated $\mathrm{CD} 8^{+} \mathrm{T}$ cells in spleen were plotted relative to spleen EBV viral loads $(n=60)$. T cell activation was analyzed by positive staining of HLA-DR by 
flow cytometry $(\mathbf{C}, \mathbf{D})$. (E) Animals were injected with $10^{5} \mathrm{EBV}$ infectious units or PBS intraperitoneally. At time of sacrifice, serum was collected and analysed for antiEBNA1 IgM antibodies via ELISA. Red lines depict the mean and dotted line represents threshold set at mean $+2 x$ standard deviation of PBS animals ( $\mathrm{PBS}=33$, EBV =71). (F) Levels of anti-EBNA1 IgM antibodies of animals above threshold were plotted relative to EBV viral loads in blood. Data shown are combined from 11 to 28 experiments. $* p<0.05, * * * p<0.001, * * * * p<0.0001$, significant comparisons are indicated. All correlations were analyzed using the nonparametric Spearman correlation, which examines rank correlation. Each symbol indicates one animal.

Fig. 5: HLA-DR15-restricted EBV-infected B cell-specific CD4 ${ }^{+}$T cell clones show cross-reactive cytokine production. Splenocyte-derived and expanded $\mathrm{CD} 4^{+} \mathrm{T}$ cells from HLA-DR15 (DR15) or HLA-DR4 (DR4) reconstituted animals stimulated by MBP, MOG or EBV peptides and analysed for IFN $\gamma$ production via ELISpot assay (A). No peptide addition served as negative control (neg ctrl) and each point indicates one well. Animals from two experiments were used (eight in total, two per experiment and condition). Schematic depiction of $\mathrm{T}$ cell cloning $(\mathbf{B}) . \mathrm{CD}^{+} \mathrm{T}$ cell clones were cloned from EBV-infected animals using bare lymphocyte syndrome lymphoblastoid cell lines (BLCLs) transfected with single MHC Class II molecules as targets using the IFN $\gamma$ capture assay. HLA-DR15 (DR15) or HLA-DR4 (DR4)-restricted CD4 ${ }^{+}$T cell clone functionality was examined through the production of the cytokines IFN $\gamma(\mathbf{C}), \operatorname{TNF} \alpha$ (D) and IL-2 (E) after 8 hours of incubation with allogeneic (allo) or autologous (auto) BLCL (HLA-DR15-expressing or HLA-DR4-expressing, depending on the genetic restriction of the $\mathrm{T}$ cell clone). To suggest the specificity of the response, allo values were additionally subtracted from auto values and included in bottom panels (C-E). 
Three HLA-DR15-restricted and two HLA-DR4-restricted CD4 ${ }^{+} \mathrm{T}$ cell clones were used and data from 5 experiments are included. Each symbol represents one well and individual clones are indicated. Lines indicate mean \pm SEM. $* * p<0.01, * * * p<0.001$, $* * * * p<0.0001$, significant comparisons are indicated and significance is based on the Mann-Whitney U test.

Fig. 6: HLA-DR15-restricted EBV-infected B cell-specific $\mathrm{CD4}^{+} \mathrm{T}$ cell clones demonstrate higher alloreactivity in cytotoxicity. $\mathrm{CD}^{+} \mathrm{T}$ cell clones were cloned from EBV-infected animals using BLCLs transfected with single MHC Class II molecules as targets. HLA-DR15 (DR15) or HLA-DR4 (DR4)-restricted CD4 ${ }^{+}$T cell clone responses are measured via target cell killing after 6 (A) and 18 hours (B), degranulation by marker CD107a surface upregulation after 8 hours $(\mathbf{C})$ and granzyme B expression after 8 hours (D) in response to the allogeneic (allo) or autologous (auto) BLCL (HLA-DR15-expressing or HLA-DR4-expressing, depending on the genetic restriction of the $\mathrm{T}$ cell clone). Allo values were additionally subtracted from auto values and included in bottom panels (A-D). Three HLA-DR15-restricted and two HLA-DR4-restricted $\mathrm{CD}^{+} \mathrm{T}$ cell clones were used and data from 2 to 5 experiments are included. Each dot represents one well and individual clones are indicated. The mean \pm SEM is depicted. $* p<0.05, * * p<0.01, * * * p<0.001, * * * * p<0.0001$, significant comparisons are indicated and significance is based on the Mann-Whitney U test. 
Fig. 1

A

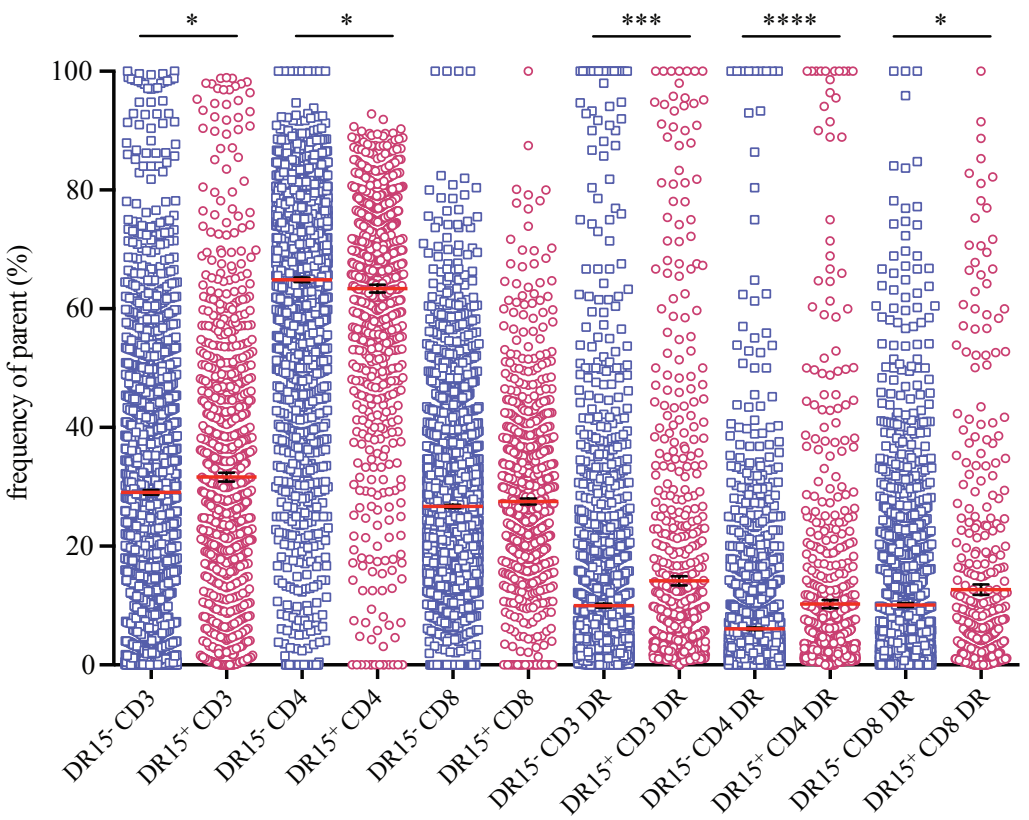

B

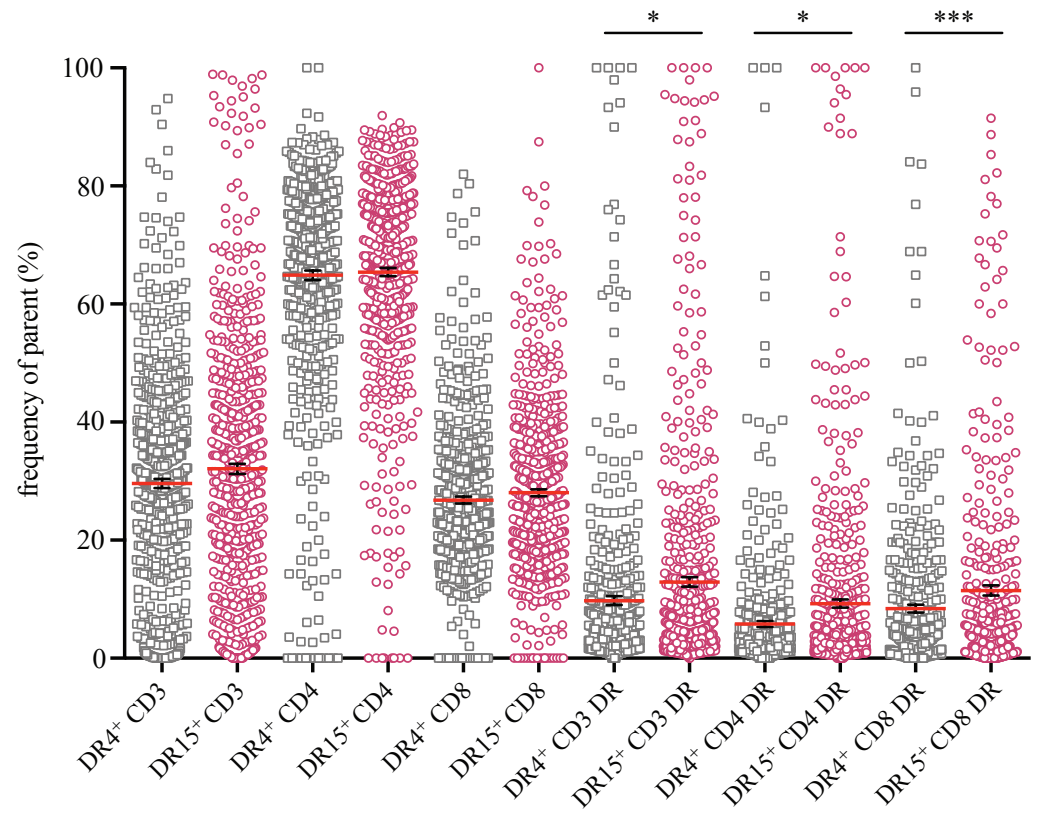


Fig. 2

A

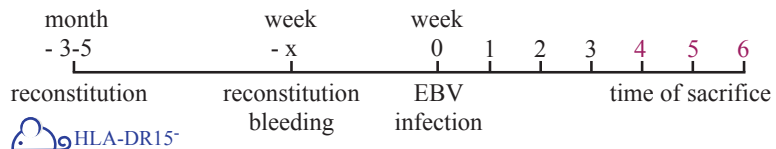

م)

B

D

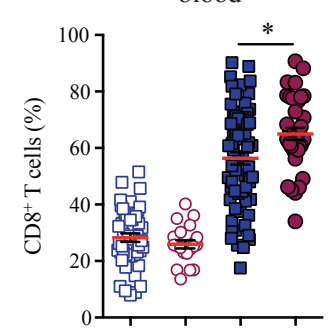

D

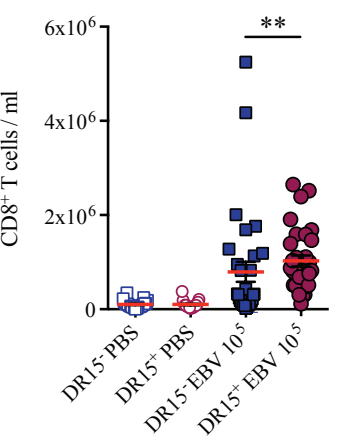

F

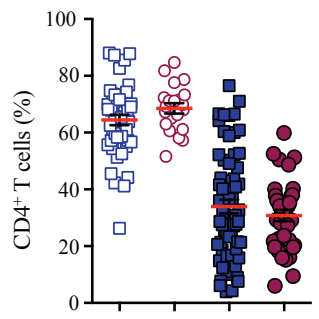

$\mathrm{H}$

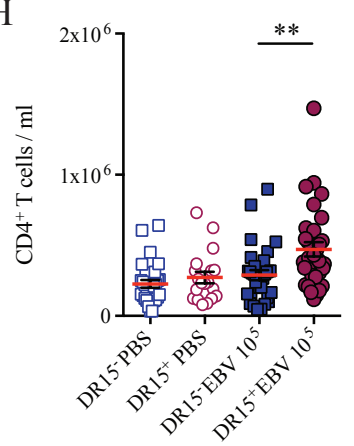

C

spleen

E

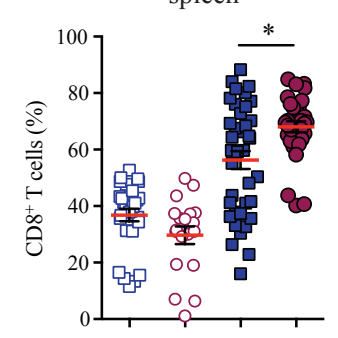

G
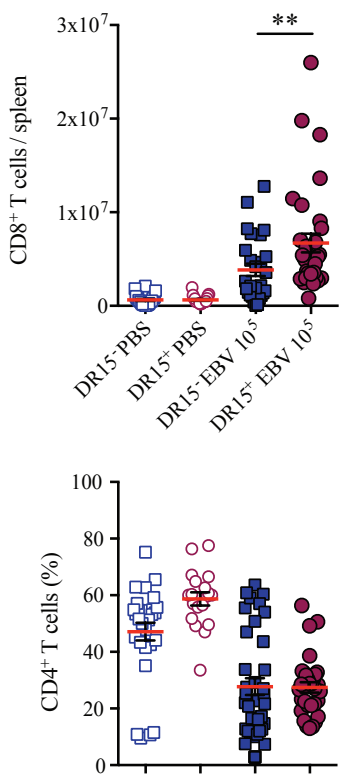

I

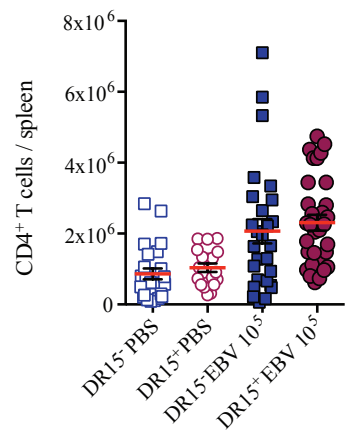


Fig. 3
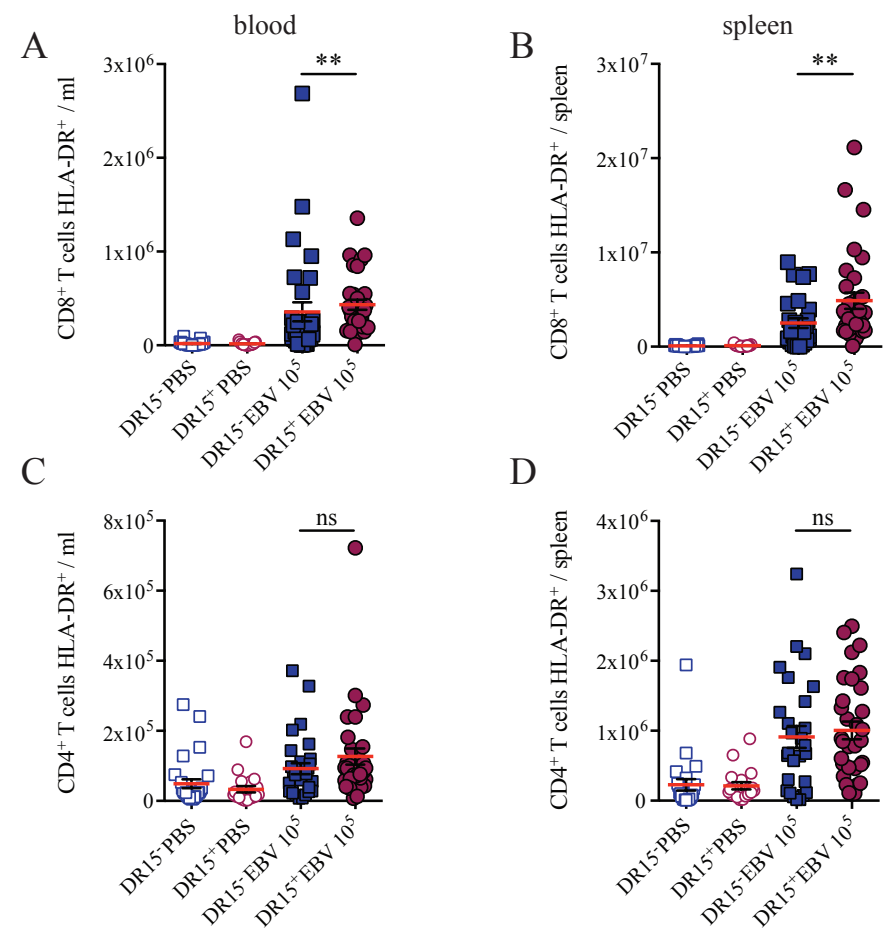
Fig. 4

A

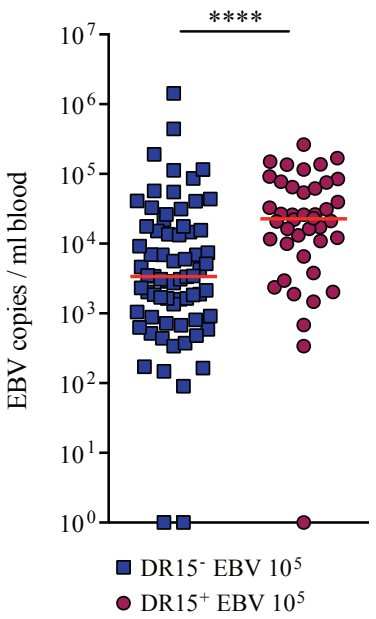

C

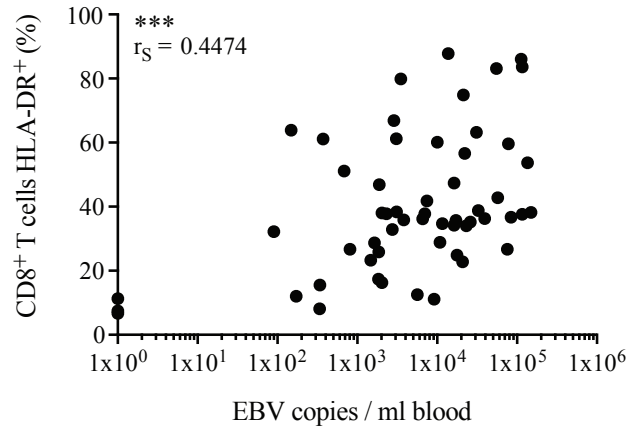

B

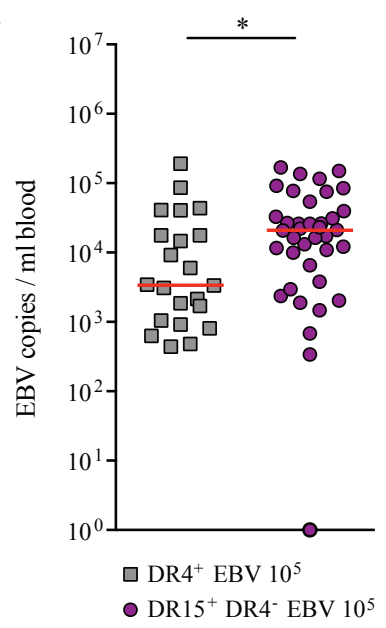

E

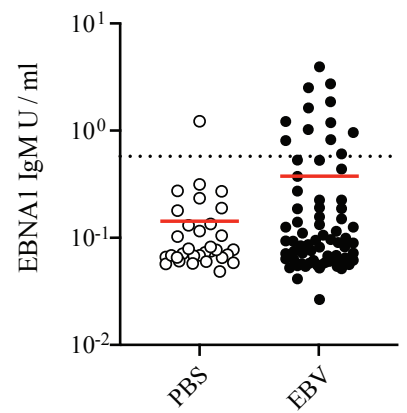

D

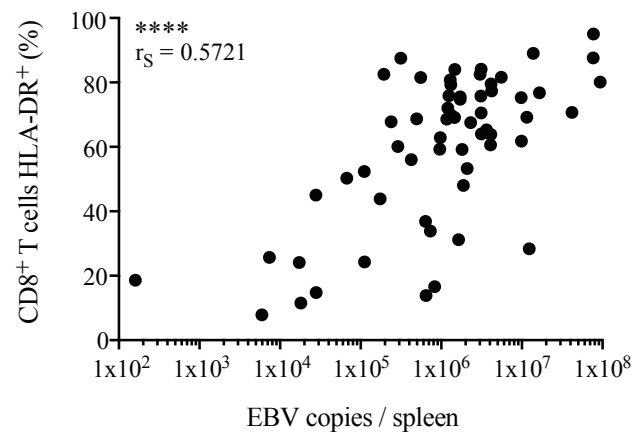

F

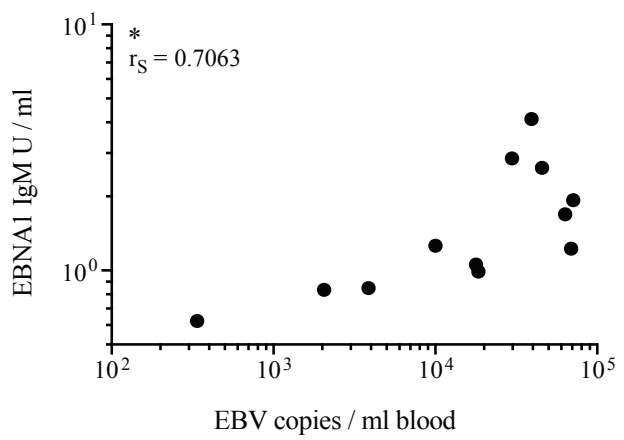


Fig. 5

A

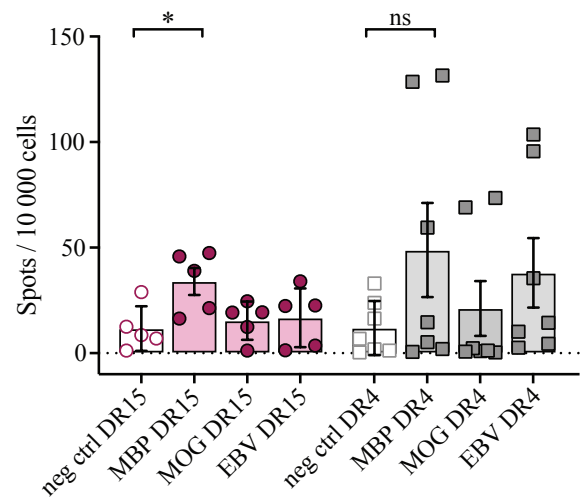

B

B cell-depleted splenocytes

HLA-DR15 ${ }^{+}$

HLA-DR4 ${ }^{+}$

matched BLCL

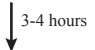

IFN $\gamma$ capture assay

dilution into 96 -well plates

$\downarrow 2-4$ weeks

IFN ${ }_{\gamma}$ screen ELISA

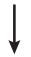

positive $\mathrm{CD} 4{ }^{+}$clones in culture
C

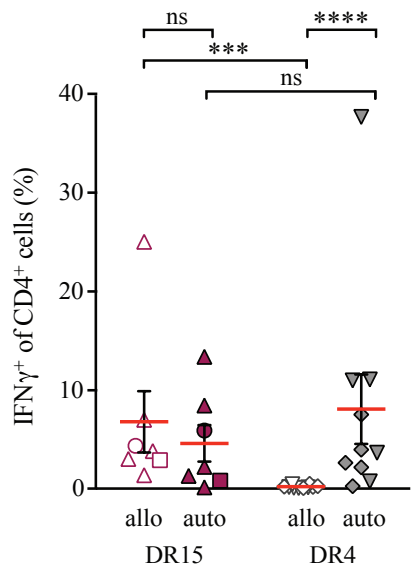

D
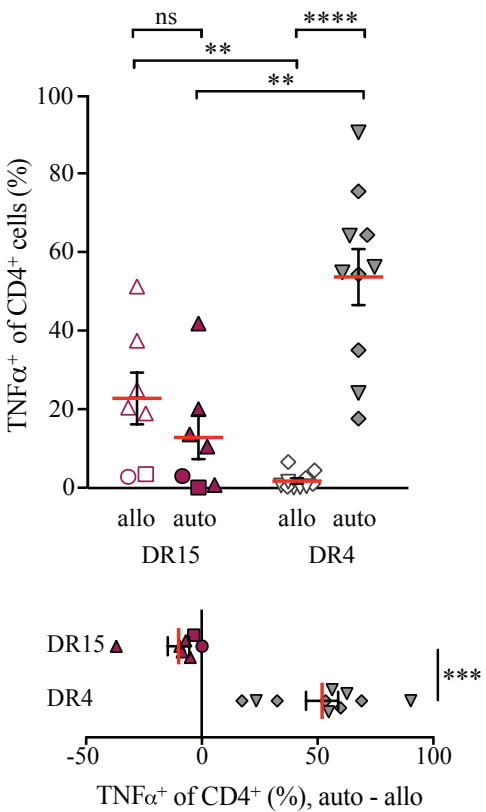

E
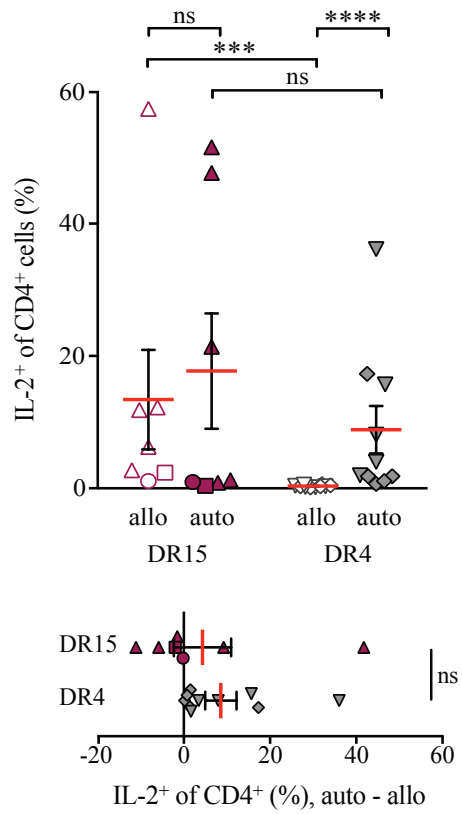
Fig. 6

A
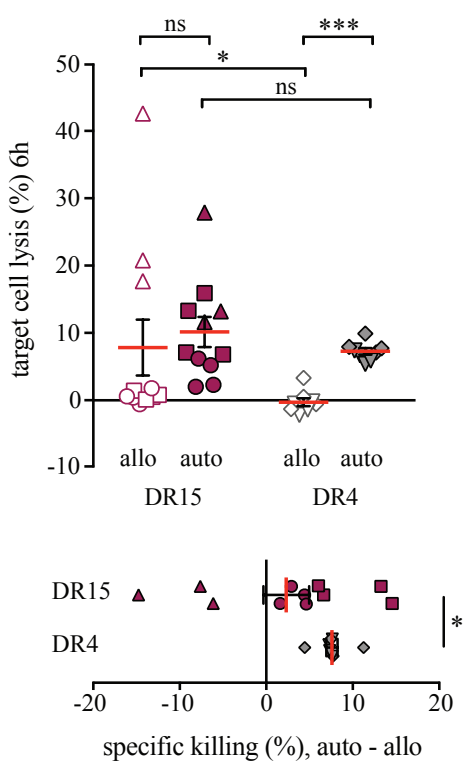

C
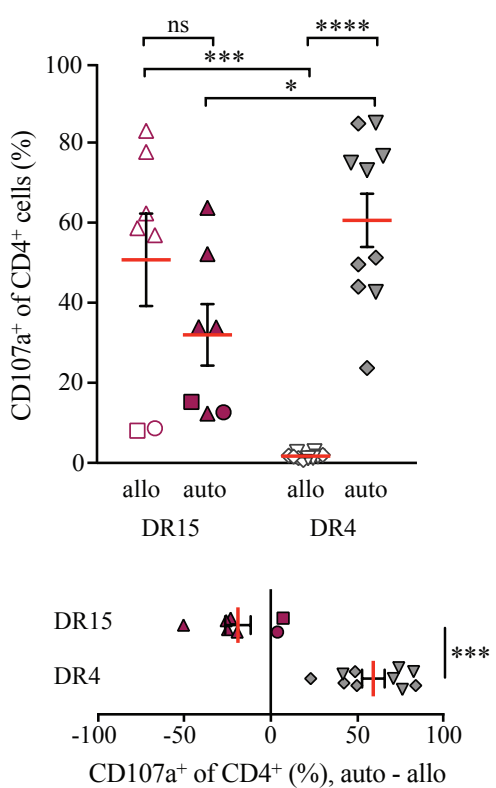

B
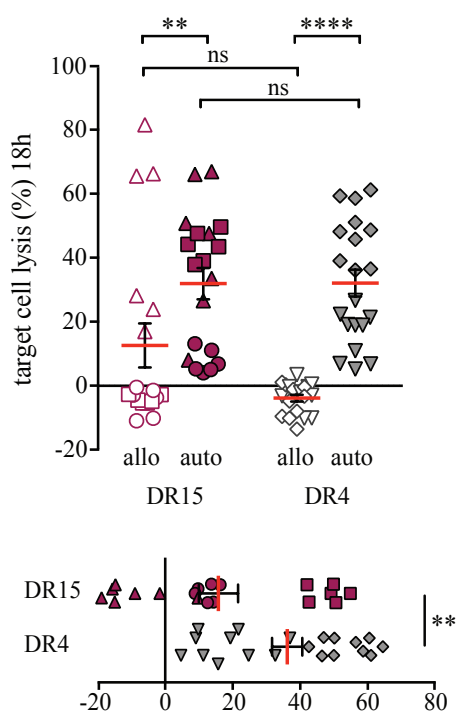

specific killing (\%), auto - allo

$\mathrm{D}$
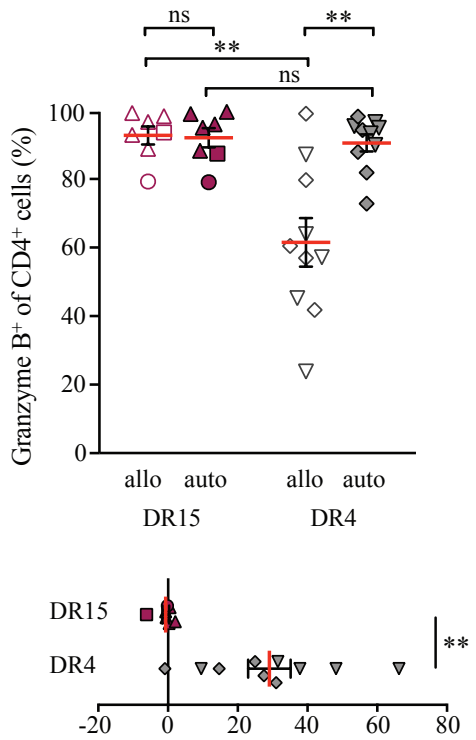

Granzyme $\mathrm{B}^{+}$of CD4 (\%), auto - allo 
Attenuated immune control of Epstein Barr virus in humanized mice is associated with the multiple sclerosis risk factor HLA-DR15

Hana Zdimerova, Anita Murer, Christine Engelmann, Anna Raykova, Yun Deng, Cornelia Gujer,

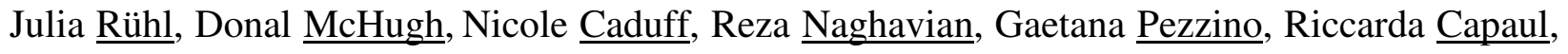

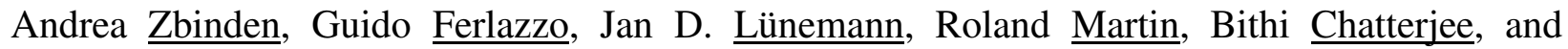
Christian Münz

\section{SUPPLEMENTARY FIGURE LEGENDS}

Supplementary Fig. 1: Gating strategy to determine reconstitution frequencies of human immune system compartments and their expression of the activation marker HLA-DR. Three months post reconstitution, animals were bled and analyzed for reconstitution of human immune system components in peripheral blood. Cells are first gated on lymphocytes, singlets, human CD45 cells, B cells $\left(\mathrm{CD} 19^{+}\right)$and $\mathrm{T}$ cells $\left(\mathrm{CD}^{+}\right)$. T cells are then further gated into $\mathrm{CD} 4^{+}$and $\mathrm{CD}^{+}$populations and $\mathrm{T}$ cell activation is analyzed by positive staining for HLA-DR.

Supplementary Fig. 2: No difference in $\mathrm{CD4}^{+} \mathrm{T}$ cell activation at steady state between HLADR4 $^{+}$and HLA-DR4- donors. Three months post reconstitution, animals were bled and analyzed for reconstitution of human immune system components in peripheral blood. Data is stratified into NSG (A) and NSG-A2 (B) animals reconstituted with HLA-DR15 negative (DR15), HLA-DR15 positive $\left(\mathrm{DR} 15^{+}\right)(\mathbf{A}-\mathbf{B}, \mathbf{D})$ HLA-DR4 positive (DR4 $\left.{ }^{+}\right)$and HLA-DR4 negative (DR4-) (C) donors. Data are pooled from both NSG and NSG-A2 animals ( $\mathrm{n}$ of animals $=2064, \mathrm{CD}^{+} \mathrm{T}$ cell activation $\mathrm{n}=1915)$ exclusive of HLA-DR15 ${ }^{+}$donors $(\mathbf{C})$. Reconstitution of B cells in DR15 ${ }^{-}$and DR15 
reconstituted animals. Data are pooled from both NSG and NSG-A2 animals ( $\mathrm{n}$ of animals $=2905$ ) (D). $* * p<0.01, * * * p<0.001, * * * * p<0.0001$, significant comparisons are indicated and significance is based on the Mann-Whitney $U$ test. Each symbol indicates one animal (mean \pm SEM).

\section{Supplementary Fig. 3: Higher total numbers and total activated $\mathrm{T}$ cells in EBV-infected}

huNSG animals. As indicated in Fig. 2A, animals were injected with $10^{5}$ EBV infectious units or PBS intraperitoneally and monitored for 4-6 weeks. At time of sacrifice (4-6 weeks post infection), frequencies of total T cells in blood and spleen $(\mathbf{A}, \mathbf{B})$, total numbers of T cells in blood and spleen $(\mathbf{C}, \mathbf{D})$ and total numbers of activated $\mathrm{T}$ cells in blood and spleen $(\mathbf{E}, \mathbf{F})$, respectively, were analysed and stratified into animals reconstituted with HLA-DR15 negative (DR15) and HLADR15 positive $\left(\mathrm{DR} 15^{+}\right)$donors. T cell activation was analyzed by positive staining of HLA-DR (E, F). Data shown are combined from 11 to 24 experiments and contain 19-65 animals per group. $* p<0.05, * * p<0.01$, significant comparisons are indicated and significance is based on the Mann-Whitney U test. Each symbol indicates one animal (mean \pm SEM).

\section{Supplementary Fig. 4: Equivalent reconstitution in humanized mouse cohorts and activated} $\mathrm{CD8}^{+} \mathbf{T}$ cells correlate to $\mathbf{E B V}$ viral load. Frequencies of initial reconstitution of human $\mathrm{CD}^{+} 5^{+}$ cells in humanized mouse cohorts, of which some animals were EBV infected (Fig. 4A, B). Reconstitution of HLA-DR15- HLA-DR15 ${ }^{+}$reconstituted animals (A) and HLA-DR4 ${ }^{+}$, HLADR15 ${ }^{+}$DR4 $4^{-}$reconstituted animals (B) is shown. (A) In left column, 70/527 animals and in right column, 42/173 animals were used for EBV infection. (B) In left column, 22/159 animals and in right column, 38/145 animals were used for EBV infection. (C) Total numbers of activated CD8 ${ }^{+}$ 
$\mathrm{T}$ cells in blood were plotted relative to blood EBV viral loads $(\mathrm{n}=52)$. (D) Total numbers of activated $\mathrm{CD} 8^{+} \mathrm{T}$ cells in spleen were plotted relative to spleen EBV viral loads $(\mathrm{n}=56)$. $\mathrm{T}$ cell activation was analyzed by positive staining of $\operatorname{HLA}-\mathrm{DR}(\mathbf{C}, \mathbf{D})$. Data shown are combined from 11 experiments. $* p<0.05, * * p<0.01, * * * * \mathrm{p}<0.0001$, significant comparisons are indicated. All correlations are analyzed using the nonparametric Spearman correlation, which examines rank correlation. Each symbol indicates one animal.

Supplementary Fig. 5: MBP reactivity, activation, T-bet and EOMES expression by HLADR15 or -DR4 positive $\mathrm{CD4}^{+} \mathrm{T}$ cells of $\mathrm{EBV}$ infected humanized mice. Splenocyte-derived and expanded $\mathrm{CD}^{+}{ }^{+} \mathrm{T}$ cells from HLA-DR15 (DR15) or HLA-DR4 (DR4) reconstituted animals stimulated by MBP peptides and analysed for IFN $\gamma$ production via ELISpot assay (A). Negative controls (cells without peptide) were subtracted from data points and each point indicates one well. Individual animals from two experiments are shown and indicated by numbers. $\mathrm{CD} 4^{+} \mathrm{T}$ cell clones were cloned from EBV-infected animals using BLCLs transfected with single MHC Class II molecules as targets. $\mathrm{CD} 4^{+} \mathrm{T}$ cell clones were incubated for 8 hours alone ( $\mathrm{T}$ only), with matched (auto) or mismatched (allo) BLCL. Their activation was analyzed by positive staining for HLADR (B), T-bet (C) and EOMES (D) transcription factor expression are shown. Data shown are combined from 4 experiments and different symbols correspond to individual $\mathrm{CD} 4^{+} \mathrm{T}$ cell clones. 


\section{Supplemental Fig. 1}

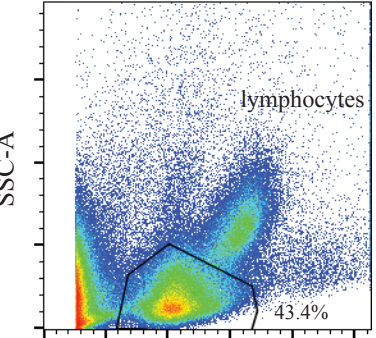

FSC-A

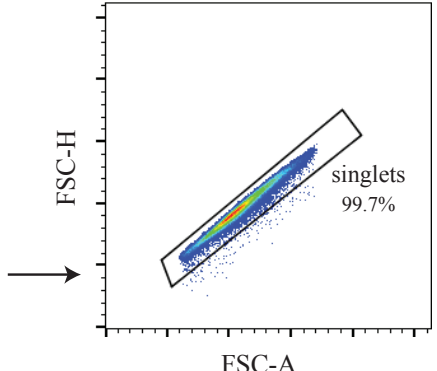

FSC-A

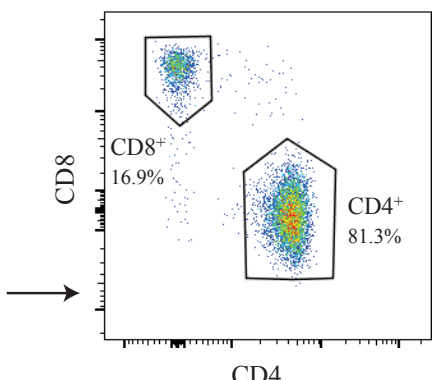

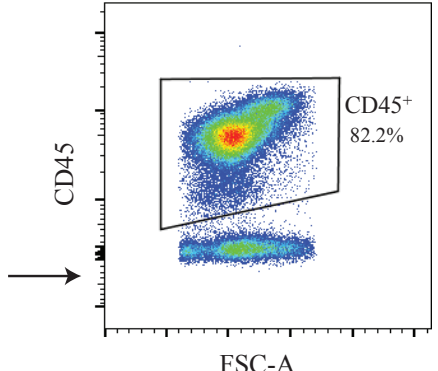

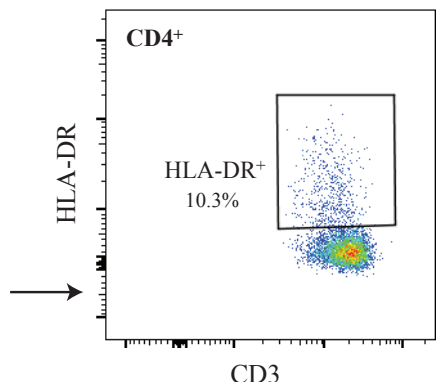

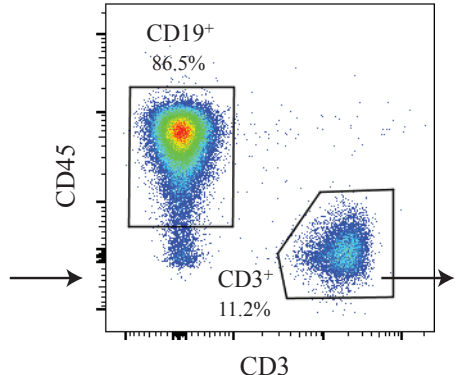

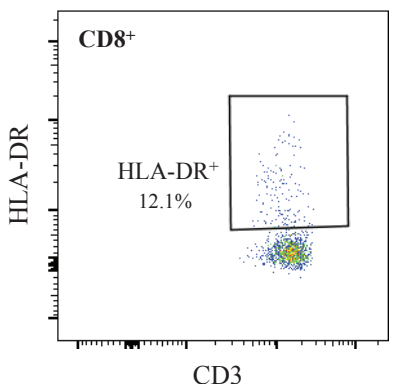




\section{Supplemental Fig. 2}

A NSG

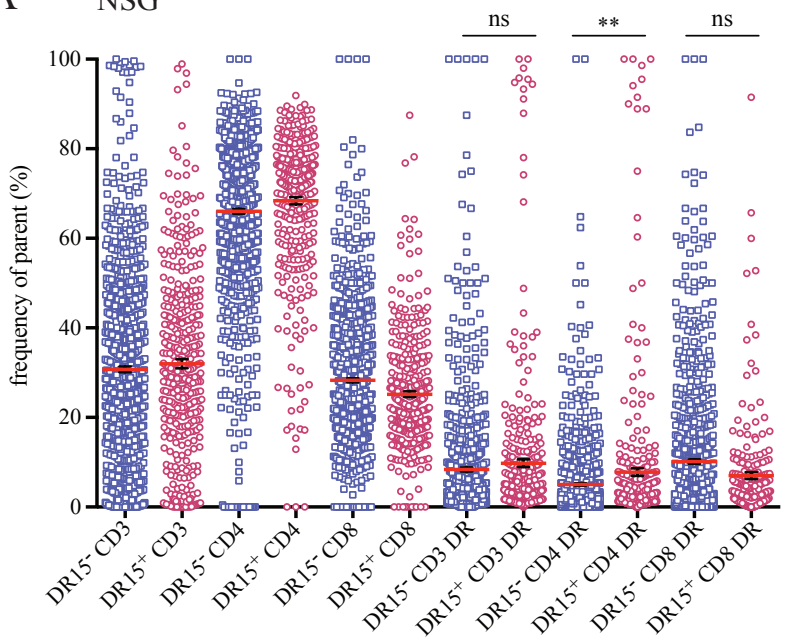

C

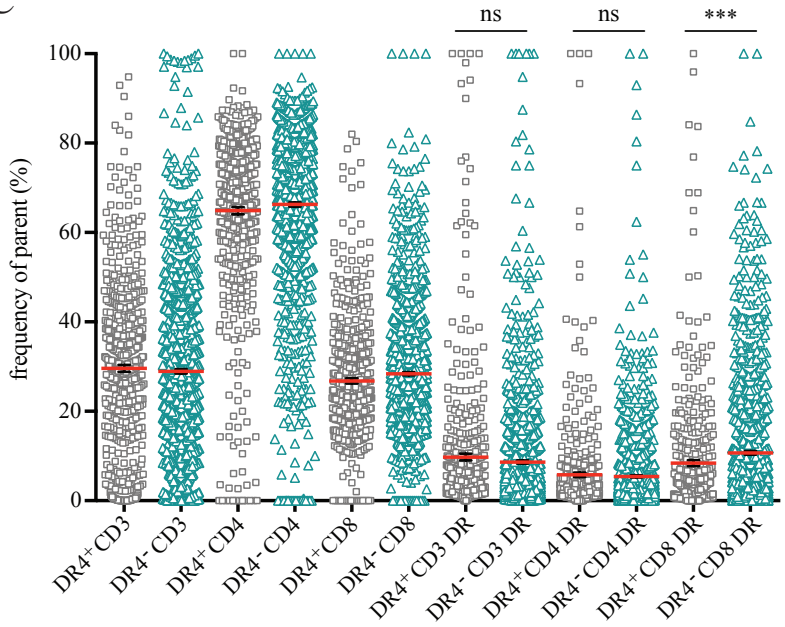

B A2

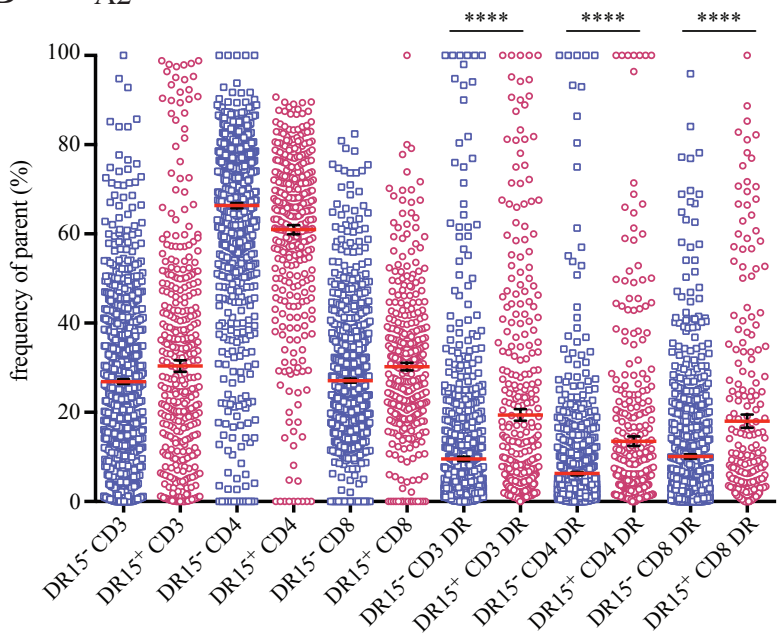

D

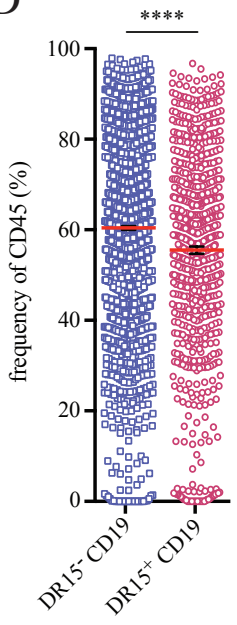


Supplemental Fig. 3

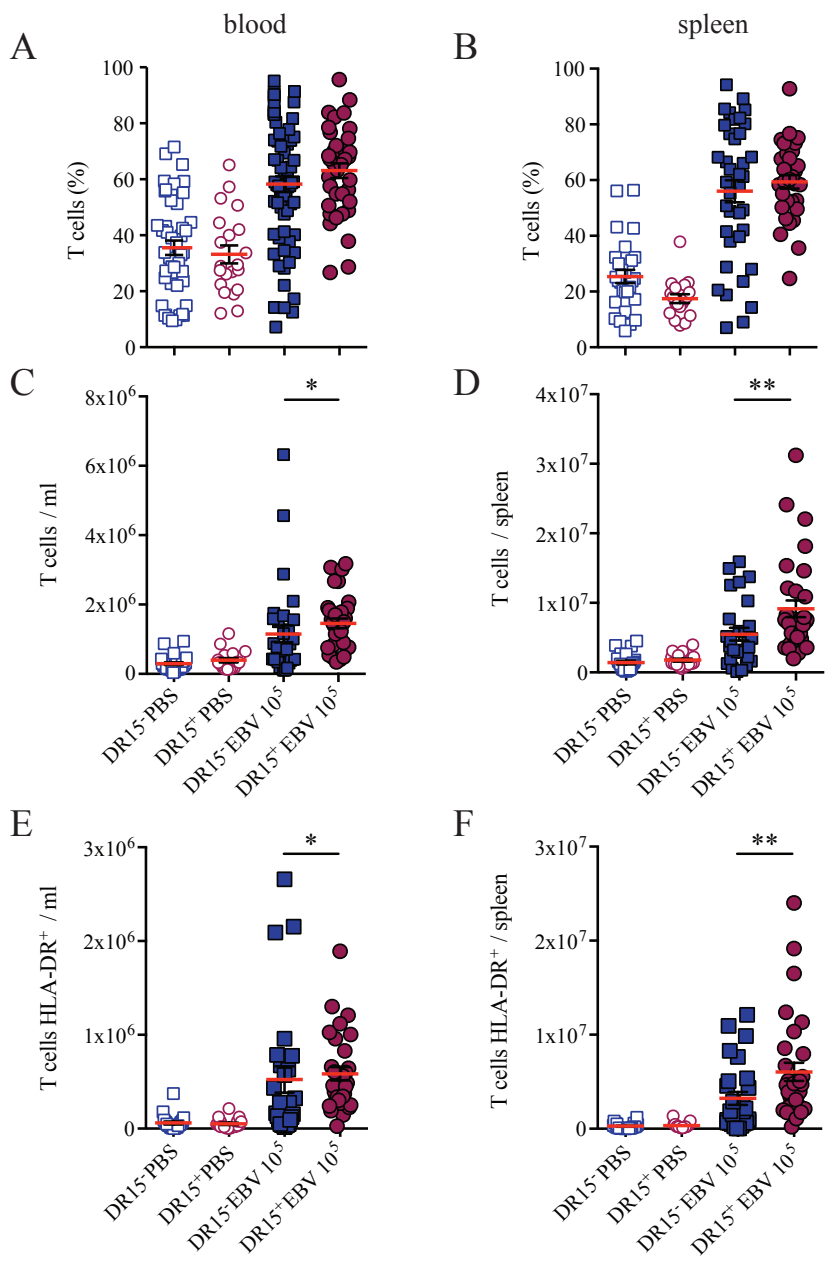


Supplemental Fig. 4

A

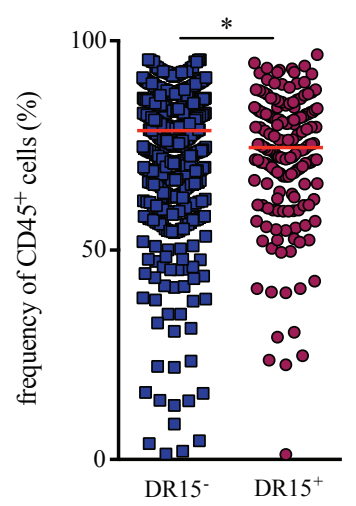

B

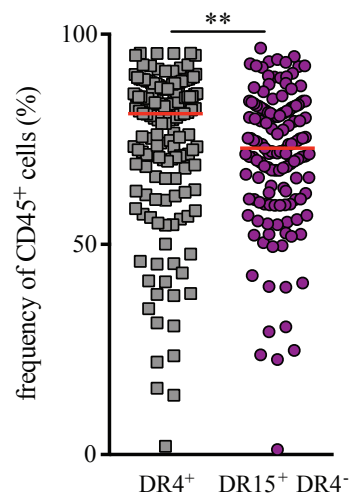

C

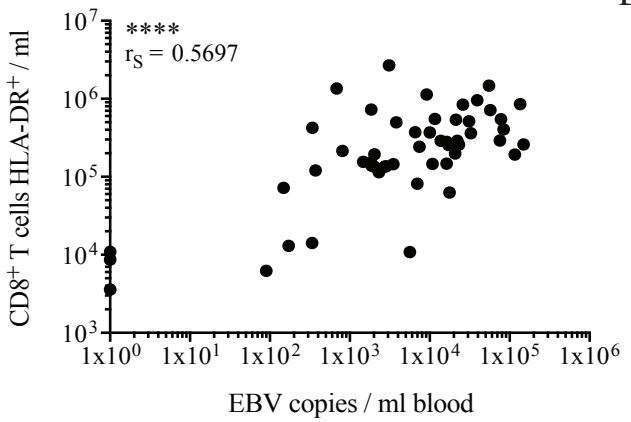

D

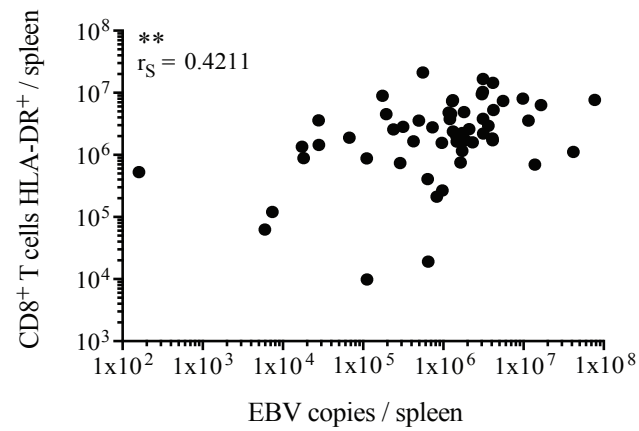


Supplemental Fig. 5

A

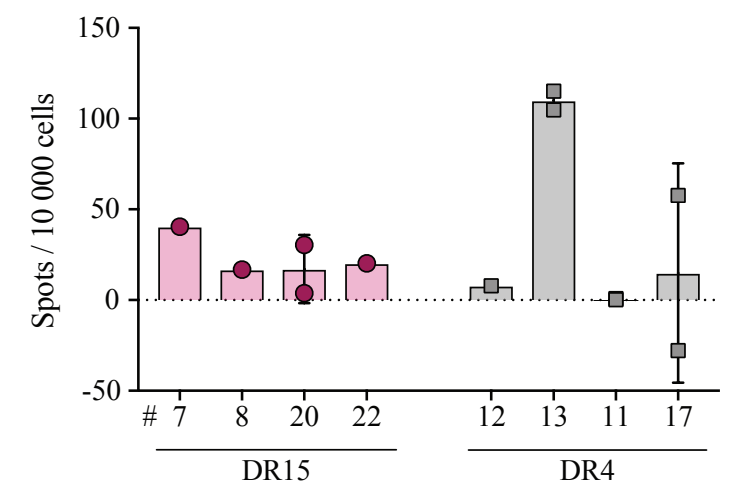

B

clone $\triangle 1.7 \quad \square \quad$ R1.3 $\quad \bigcirc \quad$ R1.6 $\quad \nabla \quad 5.1 \quad \diamond \quad 5.6$

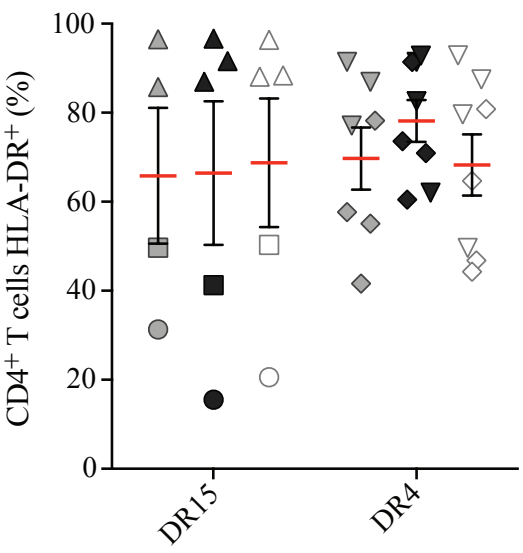

C

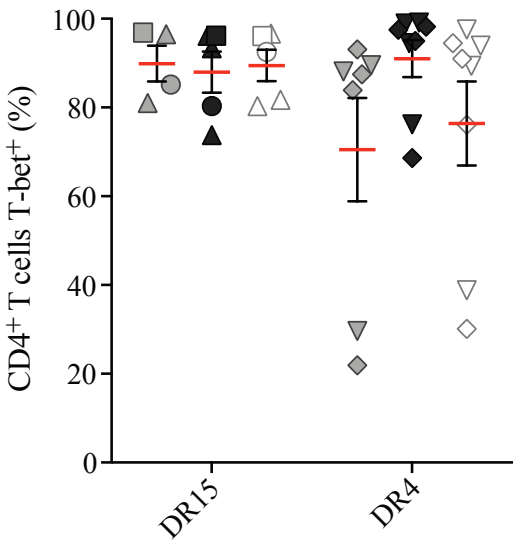

$\mathrm{D}$

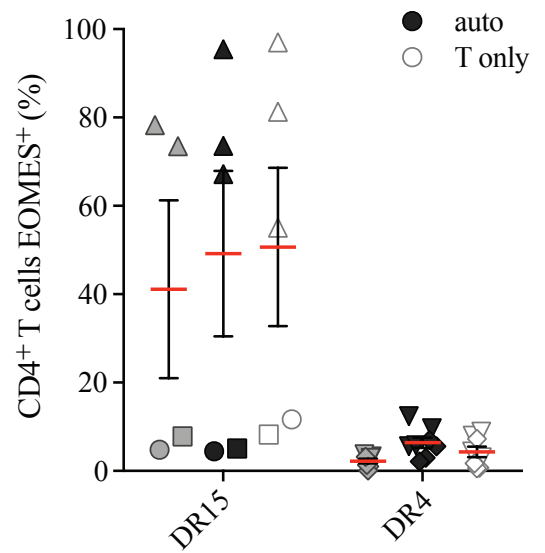

